\title{
Low-Cost Solutions for Assessment of Flash Flood Impacts Using Sentinel-1/2 Data Fusion and Hydrologic/Hydraulic Modeling: Wadi El-Natrun Region, Egypt
}

\author{
Mohammed Sadek (D), ${ }^{1,2}$ Xuxiang Li $\left(\mathbb{D},{ }^{1}\right.$ Eman Mostafa $(\mathbb{D}),{ }^{1,2}$ Mohamed Freeshah (iD), \\ Ahmed Kamal $\left({ }^{4}{ }^{4}\right.$ Mohamed Adou Sidi Almouctar $\left({ }^{1},{ }^{1}\right.$ Fubo Zhao $₫{ }^{1}$ \\ and Elhadi K. Mustafa $\oplus^{5}$ \\ ${ }^{1}$ Department of Earth \& Environmental Science, Institute of Global Environmental Change, \\ School of Human Settlements and Civil Engineering, Xi'an Jiaotong University, Xi'an 710049, China \\ ${ }^{2}$ Surveying Engineering Department, Shoubra Faculty of Engineering, Benha University, Cairo, Egypt \\ ${ }^{3}$ State Key Laboratory of Information Engineering in Surveying, Mapping and Remote Sensing, Wuhan University, \\ Wuhan 430079, China \\ ${ }^{4}$ National Water Research Center, Water Resources Research Institute, Cairo, Egypt \\ ${ }^{5}$ Department of Surveying and Geo-Informatics, Faculty of Geosciences and Environmental Engineering, \\ Southwest Jiaotong University, Chengdu 610031, Sichuan, China
}

Correspondence should be addressed to Xuxiang Li; xxli@xjtu.edu.cn

Received 1 September 2019; Revised 16 February 2020; Accepted 29 April 2020; Published 20 August 2020

Academic Editor: Giuseppe Oliveto

Copyright ( 2020 Mohammed Sadek et al. This is an open access article distributed under the Creative Commons Attribution License, which permits unrestricted use, distribution, and reproduction in any medium, provided the original work is properly cited.

Flash floods are among the most common natural hazards in Egyptian and Arabian deserts. In this work, we utilized two Sentinel1 and Sentinel-2 satellite images, before and after the flash flood, SRTM, and geolocated terrestrial photos captured by volunteers. This paper aims to three substantial objectives: (1) monitoring the flash flood impacts on Wadi El-Natrun region based on free satellite data and mapping the destroyed vegetation cover; (2) the integration of the free remote sensing data, geolocated terrestrial photos, and GIS techniques, along with hydrologic and hydraulic modeling, to evaluate the impact of flash flood hazards on the study area; and (3) assistance of the decision-makers in planning the required protective works to avoid the probable flooding. Two scenarios have been applied to estimate the flash flood effect. The first scenario has relied on Sentinel-1/2 data fusion before and after the flash flood, while the second scenario has been implemented based on the integration of the Sentinel-2 images and hydrologic and hydraulic flood modeling with the help of ArcGIS software to simulate the flash flood route. The results demonstrated that although the first scenario is an efficient solution for continuous monitoring of the change in the water bodies, it is limited in the detection of the submerged vegetation area. On the other hand, the second scenario provided the flash flood route and hydrological parameters, which determine the hazard degree of the basins, thus helping the decision-maker to manage the flood risk. Moreover, the second scenario surpasses the first one by estimating the destroyed infrastructure. Consequently, the second scenario is appropriate to assess the flash flood impacts and mitigate its influence in the future.

\section{Introduction}

Natural hazards are fundamentally regarded as the most critical challenges facing our world occurred either by rapid or slow onset events which can be geophysical (earthquakes, tsunamis, and volcanic activity) or hydrological (avalanches and floods) [1]. Among these natural hazards, the flash flood is counted the most frequent. One of the main challenges is to get a comprehensive view during the flood event with the accurate extent of the area flooded and then visualize the possible developments. Accordingly, this paper seeks to assess the impacts of the flash flood based on low-cost solution and thus assists the decision-makers [2]. 
Employing traditional surveying techniques such as ground survey (GPS and total station) in flood mapping is more expensive and time-consumer and requires skilled persons to be involved. Furthermore, if the flood event is extensive, it can be very difficult to assess and monitor its occurrence accurately and quickly [1].

Nowadays, the availability of multiple satellite data can be utilized as an efficient alternative to assess and monitor the flood case and extent in a particular area [3]. Modern remote sensing compared to traditional surveying techniques can provide overall and continuous coverage of the flood events, which assists in flood monitoring and damage assessment $[4,5]$. The modern remote sensing data have three techniques to capture valuable image data employed in flood mapping: space-borne imageries, airborne imageries, and unmanned aerial vehicle (UAV) system.

The space-borne data (optical and radar) have been immensely employed to map the inundation areas with more details and high accuracy $[4,6]$. Optical data are the preferred information source for flood and inundation mapping due to their straightforward interpretability and rich information content: true color images through which automatic classification and visual interpretation can be easily carried out to output the first-hand information of the flooded areas. Moreover, near-infrared (NIR) bands are particularly effective that they are strongly absorbed by water, yet reflected by land [1,7]. However, as flood events often occur during long-lasting periods of precipitation and persistent cloud cover, systematic monitoring by optical imaging instruments is usually impossible. This fact drastically decreases the regular utilization of space-borne optical sensors in an operational rapid mapping context.

Some of the optical satellites have many merits such as freely available data with high temporal resolution (Sentinel2 with 5 days and MODIS at daily-scale in particular). Ahmed et al. [8] have presented a hybrid methodology to evaluate the flash flood impacts using different optical systems: MODIS and Landsat-8 OLI in order to exploit their respective advantages. Despite optical satellite data positivity, their utilization can be intensely constrained because of massive cloud cover, rains, and haze during and after the flood occurrence. Sadek and Li [1] have dealt this issue confirming that fuzzy analytical hierarchy process (FAHP) is appropriate to determine the flood vulnerable area in cities, especially due to its matching with the most destroyed areas identified by the change detection between two Sentinel-2 images, before and after the flash flood. Then, the decisionmaker can trustily depend on Sentinel-2 images to estimate the flood influence over urban areas with distinct features: buildings and roads that can be clearly discriminated on Sentinel-2 images, or applying the FAHP on cities susceptible to flash floods in case of unavailable optical satellite images.

Very high-resolution images such as WorldView-3 and GeoEye-1 can provide more valuable information than Sentinel-2. Nevertheless, they have an essential demerit; expensive price is therefore still limited in their application of flash flood effects assessment. In our research, we have relied on Sentinel-2 satellite to assess flood impact on cultivation areas, which has satisfying benefits such as (1) being freely available, (2) high spatial resolution $(10 \mathrm{~m})$ for the visible bands, (3) having 13 multispectral bands, (4) just five days to completely cover the whole earth, and (5) global coverage with a wide field of view, $290 \mathrm{~km}$ [9].

Space-borne radars such as TerraSAR-X, RADARSAT-2, COSMO-SkyMed, and Sentinel-1 are used to delineate the flooded area. Sentinel-1 provides dual polarisation capability, very short revisit time (six days), rapid product delivery, and freely available data. This guarantees sufficient temporal resolution to capture the highly dynamic nature of many aquatic habitats. Sentinel-1 satellite is an active sensor that emits radar pulses and records the land surface returns at the satellite. It contributes an advantage over optical sensors by the capability of capturing images during the cloud cover presence and at night as well $[10,11]$. Giordan et al. [12] have presented the methodology for mapping river flood impacts by using multisensor data (SAR and multispectral) at multiscale, interested in free or low-cost data/ sensors. In spite of the merit of synthetic aperture radar (SAR) compared to optical systems, there are some difficulties in identifying flooding. The roughening of the water surface, generated by intensive rainfall or wind, can increase the backscattering of the radar signal, increasing the possibility of the flooded areas not to be highlighted [10,13]. The major factors that affect the strength of the radar return are concluded in notable surface roughness, dielectric properties, and local topography in relation to the radar look angle $[14,15]$.

Aerial remote sensing technology has precious advantages like low flight altitude which is not affected by clouds as well as the very high spatial resolution compared with spaceborne observations. Nevertheless, it demands more time to process plus governmental permission as well [1].

Although the UAV system was introduced as a modern remote sensing technique which is capable of capturing ultrahigh spatial resolution images, it is inconvenient in case of widespread flood since its coverage is limited.

The researchers have introduced various studies concerning the flash floods using hydrological and hydraulic inputs to be analyzed at both spatial and temporal scales. For this goal, numerical models have been used to simulate the flash flood. With the assistance of the recent modeling technology integrated with the substantial tool of Geographical Information System (GIS), the flood route map becomes more precise and consumes less time than before. Mashaly and Ghoneim [16] have used the integration of two different models: a hydrologic and a hydraulic, to simulate the flash flood impacts on the city of Quseir, Egypt.

Most of the previous research studies have addressed either the river flood or flooding caused by the collapse of dams, where the flooding water covers wide areas staying for a long time period, thus easy to monitor through Landsat satellite which has 16-day revisit time. On the other hand, this paper focuses on the flash flood which occurs within less than one day and has a destructive effect as a consequence of the water rush from top to bottom. Usually, free or low-cost data have low spatial resolution and a long revisit time, which cannot provide the assessment of the impacts of this 
type of flash floods. However, the Sentinel-1 and Sentinel-2 satellites have valuable advantages represented in high spatial and temporal resolution, 6 and 5 days, respectively $[9,17]$. The overall objectives of this study are as follows: (1) monitoring the flash flood impacts on Wadi El-Natrun region based on free satellite data (Sentinel-1/2 data fusion) and mapping the destroyed vegetation areas; (2) the integration of the remote sensing data and hydrologic and hydraulic models, along with GIS techniques for flood risk analysis; (3) support of the decision-makers in implementing the required protective works and to precisely estimate the financial compensation. The current study focuses on November 4, 2015, flood disaster in Wadi ElNatrun region. This paper has dealt with two scenarios to estimate the destroyed vegetation area.

\section{Description of the Study Area}

Wadi El-Natrun is located in the western desert of Egypt, about $90 \mathrm{~km}$ west of the Nile Delta at $30^{\circ} 14^{\prime} \mathrm{N}$ latitude and $30^{\circ} 30^{\prime} \mathrm{E}$ longitude (Figure 1). It has a depression known as Wadi El-Natrun, and its level is $23 \mathrm{~m}$ below the mean sea level (MSL). It has a unique elongated shape, and its average length is about $60 \mathrm{~km}$ and the average width is about $10 \mathrm{~km}$. Two opposite cliffs are located on this depression banks, the upper limit of the eastern cliff matches elevations of 30 to 40 meters above MSL, but the western escarpment rises up to $170 \mathrm{~m}$ above MSL. 23\% of that area lies below sea level, and the northwest sector of the depression lies $19 \mathrm{~m}$ below MSL. The entire region of Wadi El-Natrun is almost $5200 \mathrm{~km}^{2}$.

Several ephemeral lakes occupy the topographic lows taking a linear pattern of distribution as well as SE-NW axis of Wadi El-Natrun, for instance, Al-Fattah, Al-Bidah, AlHamra, and Jaar. Wadi El-Natrun city contains five villages having a linear distribution pattern along the banks of the lakes. The area, the number, and the depths of the lakes seasonally differ based on water supply and evaporation. The water supply feeding these lakes is water aquifers [18]. All drainage basins directly discharge the rainfall to Wadi ElNatrun depression where the water bodies are collected causing the destruction of the cultivated area and infrastructure. There are no previous protective actions, and the local government works hard to implement them.

The climate of the study area is generally characterized by arid status with some Mediterranean influence. The average annual temperature in Wadi El-Natrun analyzed from 1975 to 2005 by the Egyptian Meteorological Authority is $21^{\circ} \mathrm{C}$. The large amounts of rainfall concentrated between November and February at which the rainstorm was characterized by a short time period (less than one day). Accordingly, the flash flood is regarded as high-risk hazard. The study area was frequently subjected to flash floods over the years, in 2008, 2011, 2013, 2015, and 2016, but the most destructive one was the flood of 2015 where torrential rainfall $(30 \mathrm{~mm} / \mathrm{h})$ has struck the northwest margin of the Nile Delta, including the study area causing the inundation of the vegetation area. The volume of the water which struck the Wadi Natrun region is estimated as about 11 million $\mathrm{m}^{3}$ as mentioned in the municipal government report. The water level reached 2 to $3.5 \mathrm{~m}$ high with a speed of $25 \mathrm{~km} / \mathrm{h}$. Among different land uses, the vegetation class is dominant in this study area, and therefore, this research is interested in studying the flood impacts on the rural area based on two scenarios. In Wadi El-Natrun, the cultivated land is established in a strap few kilometers east of the lakes.

\section{Materials and Methods}

3.1. Space-Borne Data. The choice of the most convenient satellite data depends on many factors: (i) characteristics of the study area, (ii) spatial resolution, (iii) revisit time, (iv) time of acquisition with respect to the moment of maximum inundation, and (v) availability and cost of images [12]. The major objective of the Sentinel-2 mission is to provide highresolution optical imagery for the operational land cover and land change detection maps [9]. According to these conditions, Sentinel-2, which was launched in 2015 by the European Space Agency (ESA), is more convenient satellite data to validate urban flash flood impacts.

Sentinel-2 data consist of 13 spectral bands in the VNIR and SWIR domains. VNIR consists of 4 bands (blue, green, red, and near-infrared) at $10 \mathrm{~m}$ while SWIR includes 6 bands ( 4 narrow and 2 wider) at $20 \mathrm{~m}$, in addition to 3 bands of $60 \mathrm{~m}$ for atmospheric correction application [9].

The Sentinel-2 L1C (top-of-atmosphere) products are geometrically corrected with respect to the Universal Transverse Mercator map projection (UTM-WGS 84). Sentinel-2 images are available through the USGS Earth Explorer web browser. Since the flash flood has occurred on October 28, 2015, the images captured on August 16, 2015, and November 14, 2015, were used as pre- and post-flash flood images. Sentinel-2 images were processed based on Sen2Cor software to produce Sentinel-2 Level 2A bottomof-atmosphere reflectance values. There were no image data available before the flash flood directly owing to the clouds until August 16; that is why this date of pre-flash flood image is particularly relied on.

The availability of Sentinel-2 images before and after the flash flood provides the chance to extract the change in bare soil. Furthermore, it is possible to delineate the vegetation cover that was converted to bare soil after the flood which was neglected in previous studies.

Sentinel-1 is a two-satellite constellation with the prime objectives of land and ocean monitoring. Completion of a cycle around the earth by twin Sentinel-1A/B constellation operating takes 6 days, performing synthetic aperture radar imaging, enabling them to acquire imagery regardless of the weather. The first Sentinel-1 satellite was launched in April 2014. The Sentinel-1 dataset comprises Level 1 Ground Range Detected (GRD) data in Interferometric Wide swath mode (IW) consisting of focused SAR data that have been multilooked and projected to ground range using the WGS84 Earth ellipsoid model. The IW mode is essential for the systematic monitoring of the surface deformation and land changes [19]. The resulting images in dual polarisation, $\mathrm{VH}$ and $\mathrm{VV}$, have a dimension of $270 \times 270 \mathrm{~km}$ and a resolution of $10 \mathrm{~m}$ and can be downloaded from https://scihub. copernicus.eu/. We have utilized SAR images acquired by 


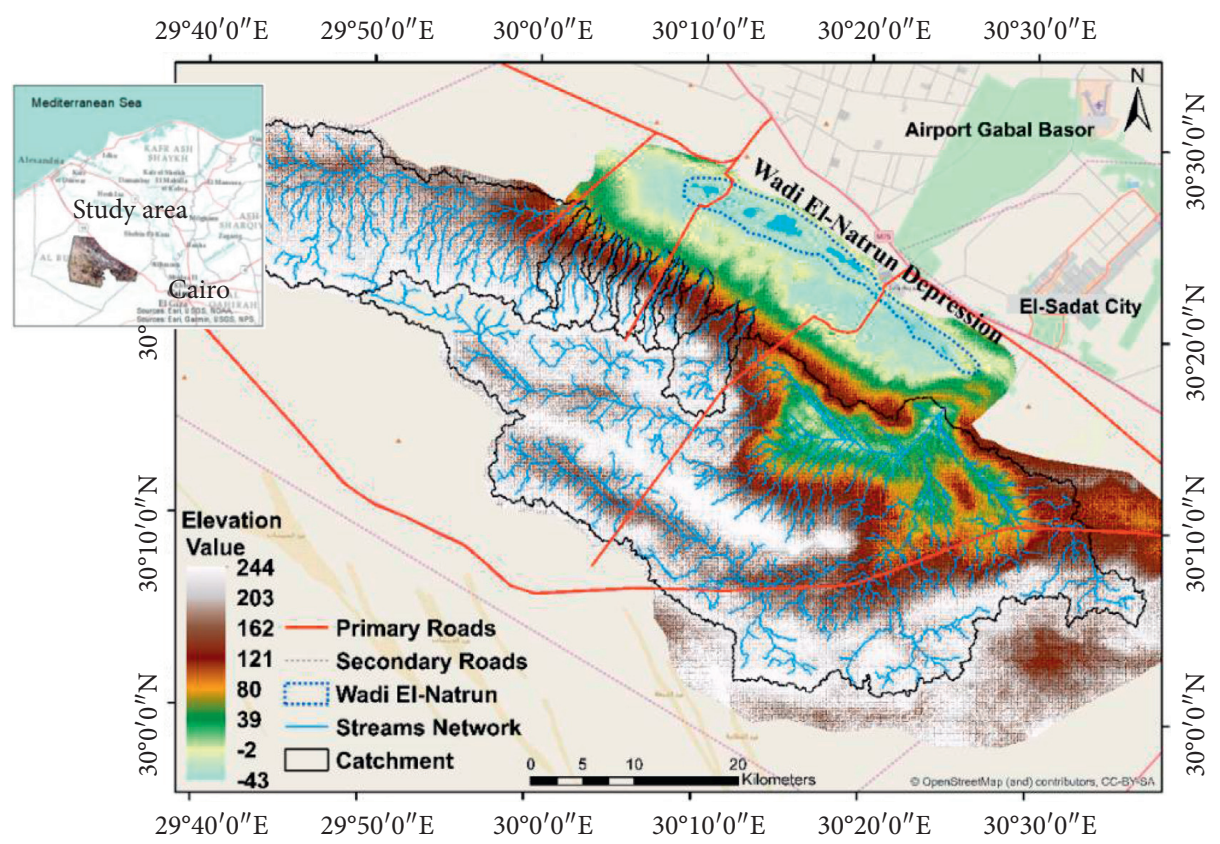

Figure 1: Wadi El-Natrun region situated in the western desert of Egypt, about $90 \mathrm{~km}$ west of the Nile Delta.

the C-band of Sentinel-1. Two scenes of S1A images (with georeference information of UTM zone 36N, WGS84) were captured on October 9, 2015, and November 14, 2015, as the pre- and post-flash flood images, respectively.

Besides the advantage of the nearly all-weather capability of acquiring useful data, a considerable benefit of SAR data for mapping flood extent is the interaction of the microwave radiation with flooded vegetation. For instance, Tsyganskaya et al. [20] have emphasized that the C-band of Sentinel-1 can successfully detect the flooded vegetation. The submerged vegetation area can often be characterized by relatively high backscatter due to either volumetric scattering from the canopy or the effect of double-bounce backscattering. The volumetric backscattering occurs when the radiation interacts with several elements of the target being scattered in multiple directions [21]. The double-bounce scattering occurs when a wave is incident on the inside corner of two flat surfaces that are joined at $90^{\circ}$ and returns back to the radar resulting in high backscattering values [22]. On the other hand, the water body surface can often be distinguished from other land cover types owing to their low backscatter response [23-25] where they appear dark, since water is a smooth surface and there is no wind, so the reflected signals scatter away from the sensor. Therefore, in comparison with the optical sensors, SAR offers the unique opportunity to detect, to a certain extent, inundation beneath vegetation. Consequently, the Sentinel-1 C-band images were used in this study for detecting both the submerged cultivation areas and the change in the ephemeral water bodies. Hardy et al. [26] have presented the use of Sentinel-1 C-band to delineate open and vegetated water bodies.

3.2. Social Media Data. One of the most important tools to get precise information about the study area are geolocated photos and reports [27-29] prepared by governmental authority or volunteers. Therefore, by searching the Internet webpages, a report of economic losses prepared by ElBuhayra local governorate and geolocated terrestrial images captured after the flood directly were found. The terrestrial images provide us the chance to validate the hydrological and hydraulic models in addition to the image classification process and thus the change detection as well. The report of economic losses has displayed the destroyed vegetation area in each crop. The total destroyed areas were 23100 ha. Because traditional techniques were used to estimate the flood impacts, this report has consumed a lot of time and effort to be prepared. To overcome that, we used modern remote sensing data for a convenient and fast methodology to estimate the destroyed cultivated area.

3.3. SRTM One Arc-Second. The Shuttle Radar Topography Mission (SRTM) was launched on February 11-22, 2000. SRTM data are successfully collected over $80 \%$ of the Earth's land surface between $60^{\circ} \mathrm{N}$ and $56^{\circ} \mathrm{S}$ latitude [30]. It has three spatial resolution outputs available, including $1 \mathrm{~km}, 90 \mathrm{~m}$, and $30 \mathrm{~m}$ resolution. SRTM DEM data are referenced horizontally to WGS84 ellipsoid and vertically to EGM96 geoid orthometric heights [31]. The SRTM elevation data for the study area were downloaded from http://earthexplorer. usgs.gov website. SRTM, 1 arc-second spatial resolution, was used to produce stream networks.

3.4. Study Methods. In general, if a flash flood strikes a vegetated area, the flash flood affects the vegetation area converting it to submerged vegetation area and/or ephemeral water bodies. When the water just penetrated the plants, the vegetation area was converted to submerged vegetation, while if the plants were entirely located below the surface of flooding water, the vegetation cover was converted 
to ephemeral water bodies. However, because the flash flood water carries soil particles, the bare soil can be one of the forms of vegetation destruction.

Based on the visual interpretation of the Sentinel-2 images before and after the flash flood, the change in the vegetation cover and the bare soil can be noticed. The methodology has involved two scenarios to estimate the destroyed vegetation area as illustrated in Figure 2. The first scenario has used two Sentinel-1 images before and after the flood to extract the submerged vegetation area and the change in the ephemeral water bodies, as we mentioned previously the capability of Sentinel-1 to extract both submerged vegetation and ephemeral water bodies. Based on NDVI, the vegetation cover before and after the flood can be sufficiently obtained. On a green canopy, the red radiation is absorbed by chlorophyll, while the near-infrared radiation is robustly reflected. This means that NDVI permits the discrimination of vegetation from soil background. The change in the bare soil can be extracted based on the classification of optical images before and after the flash flood. Accordingly, Sentinel-2 optical data are able to extract the change in the bare soil and vegetation cover.

The second scenario was implemented using the integration of remote sensing data (Sentinel-2), watershed modeling system (WMS), Hydrologic Engineering Center-1 (HEC1) model, Hydrological Engineering Centers-River Analysis System (HEC-RAS), and ArcGIS software to simulate the flash flood route. The WMS mathematical model was used to extract drainage networks, drainage basins, and morphometric characteristics in the study area. WMS is an overall graphical modeling environment for all phases of watershed hydrology and hydraulics. It involves robust tools to automate modeling processes. With the release of WMS 7, the software now supports hydrologic modeling with HEC-1 and others. In other words, WMS provides a custom interface to the HEC-1 model offering a simple way to set model parameters and a graphical user interface to run the model and visualize the results. HEC-1 is a comprehensive hydrologic modeling tool developed by the US Army Corps of Engineers and the Hydrologic Engineering Center (HEC). The model is designed to simulate rainfall-runoff processes for a wide range of watershed forms. HEC-1 uses diverse submodels to represent various components of the runoff process with the selection of abundant infiltration methods and unit hydrograph [13].

HEC-RAS, developed by the US Army Corps of Engineers and the Hydrologic Engineering Center, is a geoinformational program, an integrated system of software qualified for the simulation of the water flow in stream networks and rivers using a numerical model [32-34]. The model uses the hydrograph data resulting from HEC-1 as inputs to calculate and analyze the floodplain hydraulics [15].

The destroyed vegetation area was determined by overlaying the runoff route on the vegetation cover before the flood, extracted by the Sentinel-2 images.

3.4.1. First Scenario Using the Integration of Sentinel-1 and Sentinel-2 Images. In our analysis of the flood, we have utilized SAR images acquired by the C-band of Sentinel-1.
As shown in Figure 3, the post-flash flood image compared to the pre-flash flood one has a presentation valuable to assess and monitor the flood impacts. The red rectangles highlight the ephemeral water bodies; they are named ephemeral because these water bodies are either the ephemeral lakes whose depths and number seasonally differ based on water supply and evaporation or the vegetation cover converted to water bodies, which will automatically vanish after the cleansing works. These ephemeral water bodies appear dark, since the SAR backscattering usually gives low values in water bodies. In contrast, blue rectangles display the variation in brightness indicating the submerged vegetation areas.

Preprocessing of S1A images was implemented utilizing the Sentinel Application Platform (SNAP) software 6.0 which was presented by the European Space Agency (ESA) [17]. The S1A image processing involved five basic steps: (1) S1A images were corrected by applying orbit files. The operation of applying a precise orbit available in SNAP allows the automatic download and update of the orbit state vectors for each SAR scene in its product metadata, providing an accurate satellite position and velocity information; (2) applying the radiometric calibration which aims to convert the digital number values of the $\mathrm{S} 1$ images into backscattering coefficients $\left(\sigma^{\circ}\right)$ in a linear unit; (3) using spoke filter to remove the noise caused by the interference of waves reflected from many elementary scatterers; (4) range Doppler terrain correction algorithm with SRTM DEM was employed to output orthorectified sigma zero $\left(\sigma^{\circ}\right)$ bands. This algorithm is a correction of geometric distortions caused by topography, such as foreshortening and shadows, using a digital elevation model to correct the location of each pixel; (5) the orthorectified $\sigma^{\circ}$ band is converted to $\mathrm{dB}$ using a logarithmic transformation through the following equation: $10 \times \log 10\left(\sigma^{\circ}\right)$, and $\mathrm{dB}$ is the backscattering coefficient in decibel. Note that conversion to $\mathrm{dB}$ will award us a much better visualization where $\mathrm{dB}$ is much clearly distinguishing between the land and the water pixels. In addition, the histogram of $\mathrm{dB}$ is much easier to manipulate that it has two peaks: one peak corresponds to the pixels of the land, whereas the smaller one corresponds to the pixels of water.

We have two steps to implement the first scenario to monitor the flash flood impacts:

(a) Using Sentinel-1 to extract the submerged vegetation area and the change in the ephemeral water bodies: change detection and thresholding (CDAT) method has been utilized with the SAR imagery to extract the change in the water bodies and the flooded vegetation areas. Both are delineated based on dual polarisation VV and VH. The CDAT is a hybrid method to benefit the advantages of both techniques, where the change detection provides improved monitoring of flooded vegetation areas and separation between flooded and permanent water areas. For the thresholding technique, it is very fast and has high potential of automation and moderate complexity. However, thresholding technique may fail in 


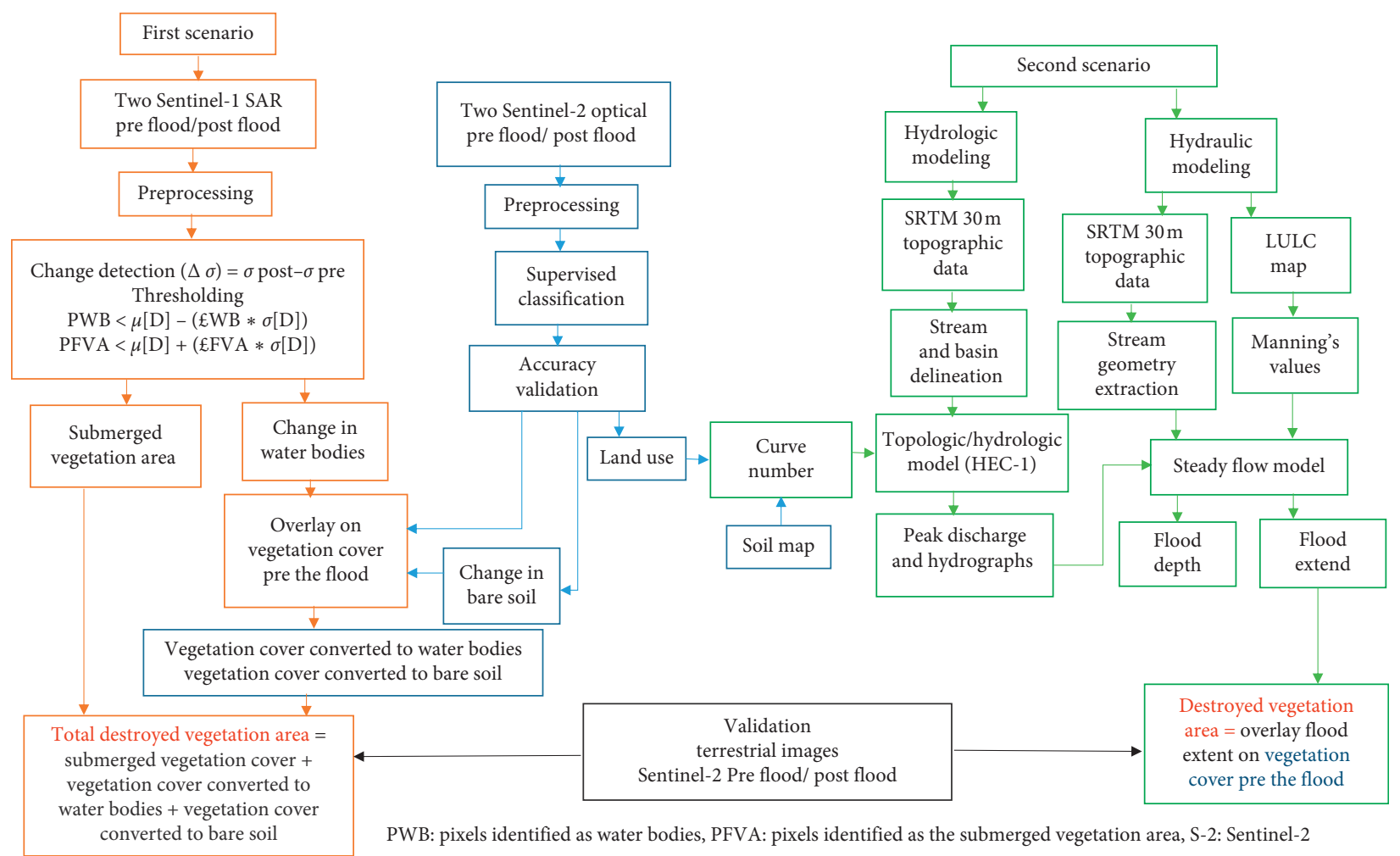

FIgURE 2: The conceptual methodology for estimating the flash flood impacts.

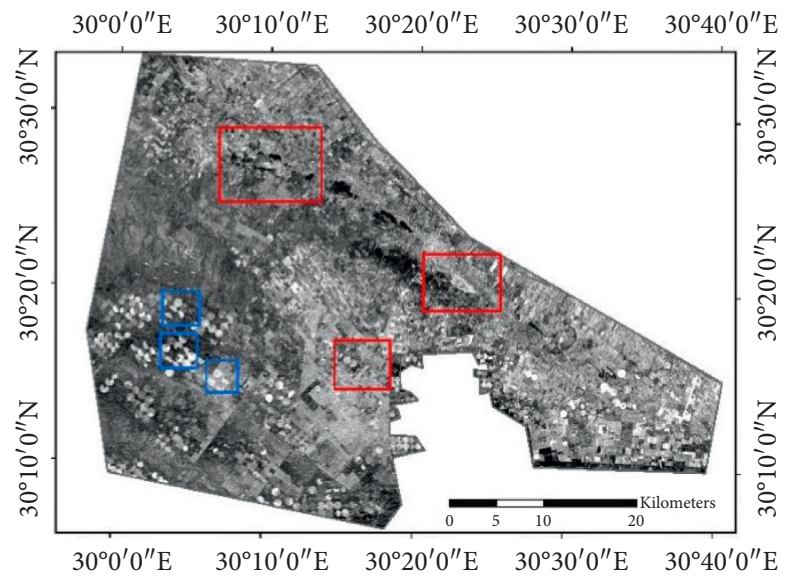

(a)

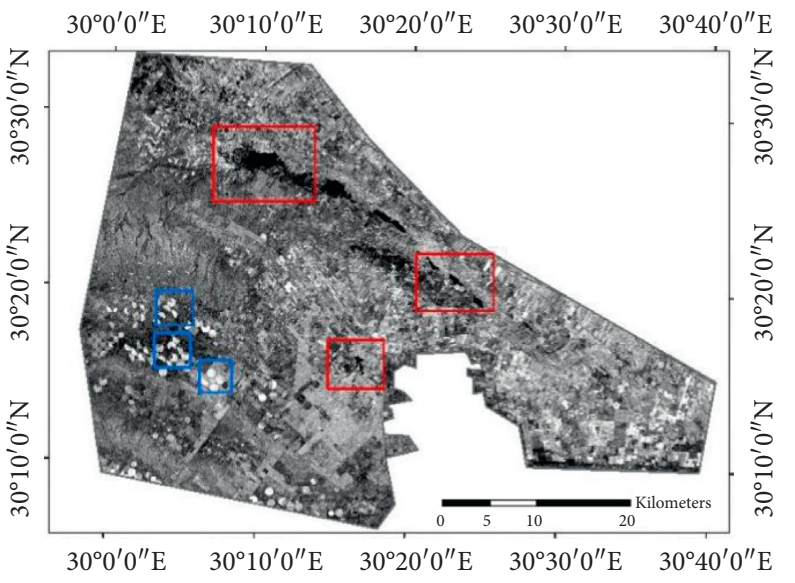

(b)

FIgURe 3: Sentinel-1 images of the study area. (a) Before the flash flood and (b) after the flash flood. The red rectangles illustrate the location of the water bodies while the location of the flooded cultivated areas is clarified via the blue rectangles.

case of low contrast between water and nonwater surfaces. The following method was then used to extract the change in the water bodies and the submerged vegetation areas:

(1) The change detection between the post- and preflash flood images was obtained by the difference of their respective backscattering coefficient $\mathrm{dB}$ $(D=\mathrm{dB}$ post $-\mathrm{dB}$ pre $)$.

(2) Thresholding. Classify the pixels of the difference image $D$ : dark pixels as the change in the ephemeral water bodies while very bright ones as flooded vegetation areas, based on a threshold for each class (see equations (1) and (2)).

Difference image has shown the change in the water bodies with negative values and flooded vegetation area with positive values. In the case of the water bodies pixels, the threshold criterion is simply that the pixel is less than the mean pixel value minus the standard deviation of the entire image multiplied by a coefficient fWB. The following criterion 
determines if the pixel (PWB) belongs to the water bodies:

$$
\mathrm{PWB}<\mu[D]-(\mathrm{fWB} * \sigma[D]),
$$

where PWB are the pixels identified as the change in the ephemeral water bodies, $\mu$ and $\sigma$ are the mean and standard deviation of the difference image $D$, and fWB is a coefficient. The ideal values of fWB were determined to be between 1.5 and 2.5 for the study area based on several iterations. Various criteria are examined during the calibration of the fWB value, including visual correlation to Sentinel-2 and identification of characteristic flooding patterns.

In the case of flooded vegetation areas, the threshold value is that the pixel is greater than the mean pixel value plus the standard deviation multiplied by a coefficient fFVA. The following criterion checks whether the pixel belongs to the submerged vegetation area:

$$
\operatorname{PFVA}>\mu[D]+(\mathrm{fFVA} * \sigma[D])
$$

where PFVA are the pixels identified as submerged vegetation areas. The optimal values of fFVA were determined to be between 1.5 and 2 for this region utilizing the same way as for the value of fWB. Values ranged from PWB to PFVA (near zero) are unchanged, representing normal water bodies before flash floods and land cover which is unaffected by the flood.

The change in the ephemeral water body layer extracted from CDAT between the two Sentinel-1 images can overlay the vegetation cover layer extracted from the Sentinel-2 image before the flood (based on NDVI) to extract the vegetation cover which was converted to water bodies.

(b) Using two Sentinel-2 images to extract the change in the bare soil and the vegetation cover: the visual interpretation is implemented on the two Sentinel-2 images based on the composition of different bands to understand the flood propagation characteristics. Figure 4 shows the Sentinel-2 images of the study area before and after the flood. These images clearly display the change in the ephemeral water bodies. The red rectangles show that the water bodies have increased after the flood event and have settled in several ephemeral lakes taking a linear pattern of distribution and scattered parts of the vegetated area. The bare soil class before and after the flash flood was extracted from the two Sentinel-2 satellite images based on Maximum-Likelihood Classification (MLC) technique. MLC is an efficient statistical method to classify objects where its results provide not only the class which a pixel belongs to but also the probability of this pixel to relate to that class. We carefully selected the training samples based on the visual interpretation and images from the site. Classification accuracy is an extremely important step to ensure precise assorted image results. Google Earth Pro and terrestrial images have an avail to validate the accuracy of the classified images. The checkpoints for evaluating the classified images are selected in a way that the number of point samples for a category is proportional to the size of that category, and the points have to be well distributed, for more realistic classification accuracy [35]. Thus, the change in the bare soil can be attained based on the change detection between the two classified images. NDVI index was used to extract the vegetation cover before the flood where the threshold value for the vegetation is identified based on the visual interpretation.

The obtained change in the bare soil layer overlaid the vegetation cover layer extracted from the Sentinel-2 image before the flood to extract the vegetation cover which was converted to bare soil.

\subsubsection{Second Scenario Using the Integration of Hydrologic/} Hydraulic Modeling. The lack of hydrological and meteorological data in this region necessitates the use of a hydrological modeling approach to predict the spatial extend, depth, and velocity of the floodwater and hence locate sites at risk of flood. Therefore, the second scenario has been implemented by the integration of remote sensing data and hydrologic and hydraulic models with the support of GIS to simulate the behavior of the flash flood route in the downstream area of both subbasins and main basins where Wadi El-Natrun depression locates $2 \mathrm{~km}$ far from the outlets of the main basins. Accordingly, the mainstream of each main basin is extended to discharge in the ephemeral lake through Wadi El-Natrun depression. The vegetation cover concentrated in the downstream area of the main and subbasins and consequently the destroyed vegetation area can be determined when the runoff route overlaid the vegetation cover before the flood.

This scenario has been executed in two steps. The first one is applying the hydrologic modeling, through WMS 7.1 and HEC-1, to calculate the morphometric characteristics, hydrographic flow of different drainage basins, peak discharge, and water volume, which represent major data used in the next step. The second stage is the two-dimensional hydraulic modeling implemented using HEC-RAS 5.0.5 and ArcGIS 10.3 software to simulate the flash flood route and depths. Basin area, catchment slope, relief ratio (Rr), drainage density $(\mathrm{Dd})$, basin ruggedness number $(\mathrm{Rn})$, and land cover types are among the morphometric features that can be utilized to describe the hydrological response of the basin [16]. Relief ratio indicates the steepness of a watershed. Drainage density is a useful numerical measure of basin analysis and runoff potential which indicates the efficiency of the basin in removing the excess rainfall. Ruggedness number indicates the structural complexity of the terrain associated with the relief and the drainage density. Generally, the peak discharge rises with increasing catchment 


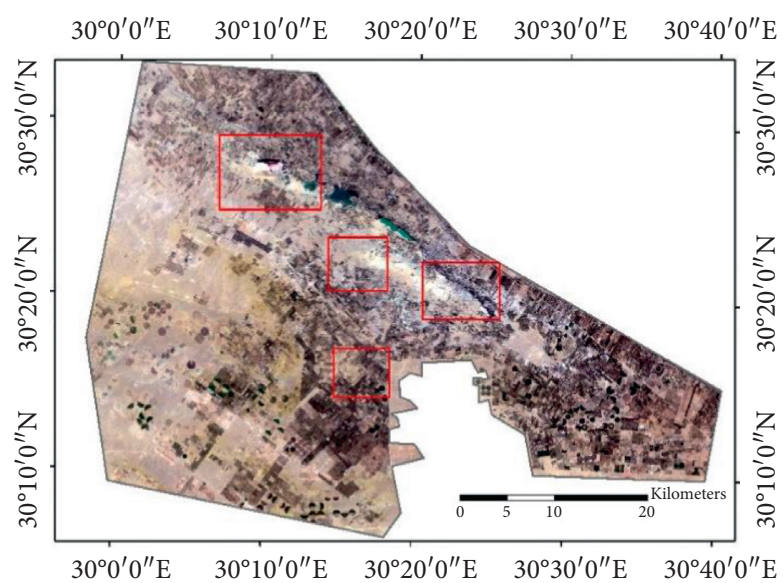

(a)

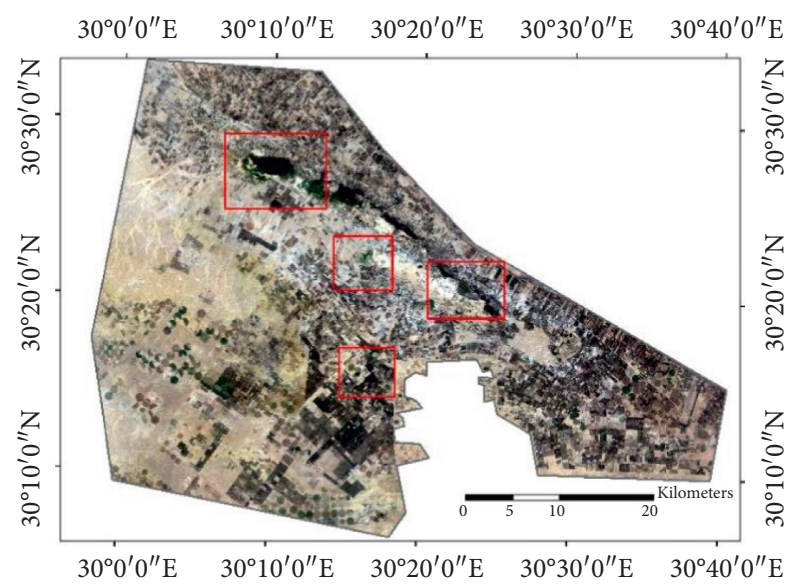

(b)

FIGURE 4: Sentinel-2 images of the study area. (a) Before the flash flood and (b) after the flash flood. Based on the visual interpretation, the water bodies concentrated in Wadi El-Natrun depression are highlighted by red rectangles.

ruggedness as a result of the increased stream density and basin relief. Based on these characteristics, the hazard degree of each basin can be determined. The basin with high peak discharge, high drainage density, high curve number, and large area becomes the most dangerous basin which could lead to massive flash floods and losses in the agricultural sector.

In the first step, to extract the stream networks and basin boundary which affect Wadi El-Natrun region, various data sources were utilized, in particular free digital elevation model SRTM $30 \mathrm{~m}$ which was acquired by Earth Explorer website (http://earthexplorer.usgs.gov). The stream networks were automatically extracted using the WMS based on topographic parametrization (TOPAZ) technique (compute TOPAZ Flow Data command in the Drainage menu). This technique uses the eight-point pour method to determine the direction of flow. The topographic maps (1:50,000 scale) obtained from the Egyptian General Survey Authority were utilized to verify the streams and catchment. Moreover, fortunately, the available geolocated terrestrial photos and Google Earth images in addition to the Sentinel-2 satellite image provide the chance of further validation for wadis based on the visual interpretation.

Floodwaters that may be lost through infiltration were estimated using the Soil Conservation Service (SCS), formerly known as the curve number (CN) (equations (3) and (4)). This method uses geological data to determine a unique $\mathrm{CN}$ value for each basin, which will be further utilized to calculate the runoff from the rainfall on the catchment area. The depth of direct flood in the catchment was estimated to derive the total quantity of floodwater from the actual rain value using the following equation:

$$
Q=\frac{(P-0.2 \mathrm{Sr})^{2}}{(P+0.8 \mathrm{Sr})},
$$

where $Q=$ depth of runoff $(\mathrm{mm}), P=$ depth of precipitation $(\mathrm{mm})$, and $\mathrm{Sr}=$ maximum potential retention $(\mathrm{mm})$ which is given by

$$
\mathrm{Sr}=25.4\left(\left(\frac{1000}{\mathrm{CN}}\right)-10\right)
$$

where $\mathrm{CN}$ is the curve number. Tables which provide $\mathrm{CN}$ values are presented in several hydraulic literature studies [36].

The Kirpich equation [37] was utilized to estimate the time of concentration (equation (5)) which is the time required for runoff to travel from the hydraulically most distant point in the watershed to the outlet:

$$
T_{\mathrm{c}}=0.0195\left(\frac{L^{0.77}}{S^{0.385}}\right),
$$

where $T_{\mathrm{c}}=$ time of concentration ( $\left.\mathrm{min}\right), L=$ maximum flow distance $(\mathrm{m})$, and $S=$ maximum flow distance slope (\%).

The lag time is defined as the time difference between the peak rainfall and the peak discharge that occurs as a result, which was calculated according to the SCS guidance (equation (6)). Furthermore, peak discharge $\left(\mathrm{m}^{3} / \mathrm{s}\right)$ was estimated for each catchment using equation (7), and the time of the greatest drainage was calculated using equation (8):

$$
\begin{aligned}
T_{\mathrm{LAG}} & =\frac{L^{0.8} *(\mathrm{Sr}+1)^{0.7}}{1900 \sqrt{Y}}, \\
\mathrm{qP} & =\frac{0.208 A Q}{T_{\mathrm{P}}} \\
T_{\mathrm{P}} & =\Delta \frac{t}{2}+T_{\mathrm{LAG}},
\end{aligned}
$$

$T_{\mathrm{LAG}}=$ lag time (hours); $Y=$ basin slope (\%); $\mathrm{qp}=$ peak discharge $\left(\mathrm{m}^{3} / \mathrm{s}\right) ; A=$ drainage area $\left(\mathrm{km}^{2}\right) ; T_{\mathrm{p}}=$ time until the peak (hours); and $\Delta t=$ duration of designed stormwater.

In the SCS method, the duration of the stormwater is assumed to be 24 hours [38]. The distribution of SCS type II was selected as appropriate for humid, semiarid, and arid conditions where it relies on an assumption that about $60 \%$ of the rainfall concentrates in two hours and the remaining 
rainfall is distributed over the day [39]. All the derived parameters were employed in the HEC-1 model to create the flow hydrographs and the peak discharge of the main and subbasins.

The $\mathrm{CN}$ for each drainage basin can be assigned using declared tables [40] including the following information: land cover, antecedent soil moisture condition (AMC), and hydrological soil group (HSG).

HSG indicates the infiltration amount that the soil can allow. They were classified according to the infiltration rates into four groups: A, B, C, and D as high, moderate, slow, and very slow, respectively [41]. The digital soil map was charted by on-screen digitizing of a paper-backed geological map (1: 250,000 scale). The soil map has indicated that the study area is composed of two materials, Calcaric Fluvisols and Gleyic Yermosols, which have been assigned to group C. The landuse/land cover (LULC) map is the classified Sentinel-2 satellite image based on the MLC technique. Both the soil and LULC maps were used to assign the curve number for each catchment.

Curve number ranges from 0 to 100 , indicating the response of water to the LULC classes in the drainage basins. The AMC is defined as the initial moisture condition of the soil prior to the storm event of interest. In the SCS methodology, three categories of AMC were presented (I, II, and III) based on seasonal limits for the total 5-day antecedent rainfall [42]. In our paper, we have used the web page Jaxa Global Rainfall Watch that provides hourly global rainfall maps in near real time using the combined MW-IR algorithm with satellite-based weather monitoring systems (online) available at http://sharaku.eorc.jaxa.jp/GSMaP/ index.htm to estimate the rainfall 5 days before the flood event.

In general, $\mathrm{CN}$ is calculated for AMC II and then adjusted up to simulate AMC III or down to simulate AMC I. In our case, the $\mathrm{CN}$ corresponds to AMC I.

Once the digital data have been collected, the typical process to calculate the $\mathrm{CN}$ for each basin area is performed as follows: (a) map the boundaries of the basins for which $\mathrm{CN}$ will be estimated; (b) determine the area of the basins and map the soil types and LULC for the basins of interest; (c) transform the soil types to HSGs; (d) overlay the LULC on HSG maps to determine each unique LULC-soil group polygon, and define the area of each polygon; (e) specify a $\mathrm{CN}$ to each unique polygon, based on SCS curve number; (f) overlay the basin map on the LULC-soil group polygons; (g) estimate the CN for each basin by area-weighting the LULCsoil group polygons within the basin boundaries.

The basic formula for $\mathrm{CN}$ estimation is shown in the following equation:fd9

$$
\mathrm{CN}_{\mathrm{aw}}=\frac{\sum_{i=1}^{n}\left(\mathrm{CN}_{i} * A_{i}\right)}{\sum_{i=1}^{n} A_{i}},
$$

where $\mathrm{CN}_{\mathrm{aw}}$ is the area-weighted $\mathrm{CN}$ of the basin, $\mathrm{CN}_{\mathrm{i}}$ and $A_{\mathrm{i}}$ are, respectively, $\mathrm{CN}$ and area for each LULC-soil group polygon, and $n$ is the number of polygons in each basin.

In the second step, among the required inputs for the hydraulic modeling are Manning's value, the derived geometric data, and the obtained peak flow. The Manning value or the roughness coefficient was gained from land-use information. The geometric data were extracted from the DEM using HEC-GeoRAS. The peak discharge was calculated by HEC-1.

By integrating the HEC-RAS hydraulic model and ArcGIS software, the flash flood simulation can be implemented in three steps:

(a) Extraction of the stream networks (based on TOPAZ), which can be beneficial in the creation of the stream centerline of the subbasin. The stream centerline of the main basin is delineated via on-screen digitization of the post-flash flood Sentinel-2 image where the water flow path clearly appears.

(b) Preprocessing of the geometric data in HECGeoRAS: the geometric data which include stream centerline, banks, flow path centerline, and crosssections were extracted from the DEM using HECGeoRAS extension (the connection between HECRAS and ArcGIS programs) dedicated to run on ArcGIS [43]. The HEC-GeoRAS tool is an extension of the HEC-RAS improved by the collaboration between Environmental Systems Research Institute (ESRI) and Hydrologic Research Engineering Center (HEC), supporting the pre- and postprocessing of the geometric data implemented in HEC-RAS. https://www.utdallas.edu/ brikowi/Teaching/ Applied_Modeling/SurfaceWater/WMS/Tutor71. pdf

(c) Postprocessing of the data information in HEC-RAS and the flood simulation: in this stage, by importing the derived geometric data and inserting the peak discharge and Manning value in HEC-RAS, the flash flood route and water depth map can be output.

\section{Results}

4.1. First Scenario. According to the conceptual methodology of the first scenario, it is clear that the destruction of the vegetation cover caused by the flash flood event appears in three forms: (1) the submerged vegetation area (2) the vegetation area converted to water bodies, (3) and the vegetation area converted to bare soil.

The results of the CDAT technique carried out on the two Sentinel-1 images indicate that based on the $\mathrm{VV}$ and $\mathrm{VH}$ polarisation images, the change in water bodies was 9809.9 ha and 9897.3 ha whereas the submerged vegetation areas were 5970.8 ha and 7169.7 ha, respectively.

Similarly, to identify the vegetation cover converted to ephemeral water bodies, the change in the ephemeral water bodies extracted from the two Sentinel-1 images has overlaid the vegetation cover before the flood extracted from Sentinel-2 image. The vegetation cover converted to ephemeral water bodies was 5371.3 ha based on VV polarisation and 3530.7 ha based on $\mathrm{VH}$ polarisation.

Now it is possible to identify the vegetation areas which were converted to water bodies or bare soil along with the 
submerged vegetation area extracted from the CDAT technique between the two Sentinel-1 images.

In this study, based on Sentinel-2 images, totally six LULC classes were specified as water, vegetation, bare soil, buildings, roads, and desert. Accuracy assessment is expressed through overall accuracy and kappa statistic which were derived from the error matrix for the classified pre- and post-flash flood images as $87 \%, 0.83,86 \%$, and 0.82 , respectively. The flash flood has caused massive damage to the vegetation sector. Before the flash flood, the areas of bare soil have been 315523 ha, while after the flash flood, they have reached 353908 ha. It is clear that the areas of bare soil have increased as a form of vegetation cover destruction. By overlaying the change in the bare soil layer on the vegetation cover before the flood extracted from the Sentinel-2 image, the vegetation cover converted to bare soil can be extracted as 6777.7 ha.

In other words, the outputs of the first scenario include a map of the destroyed vegetation cover classified into the possible probabilities. Therefore, the total destroyed vegetation area based on $\mathrm{VV}$ and $\mathrm{VH}$ polarisation represented 18119.8 and 17478.2 ha, respectively (see Figure 5), by adding the two outputs from Sentinel-1 analysis and the third output from Sentinel-2 analysis.

To validate the outputs of the first scenario, we relied on the geolocated terrestrial images along with the change in the vegetation cover from the Sentinel-2 scenes which represent the destroyed vegetated area. Random points were distributed based on visual interpretation, and these points are chosen with proportionality to cover both of the destroyed and undestroyed vegetation areas, to obtain realistic classification accuracy. The accuracy assessment of both $\mathrm{VV}$ and $\mathrm{VH}$ polarisation is shown in Table 1. The kappa coefficient varies from 0.75 for $\mathrm{VV}$ to 0.70 for $\mathrm{VH}$, showing a satisfying matching between the Sentinel-2 optical result and the VV$\mathrm{VH}$ polarisations. As the overall accuracy and kappa coefficient are higher for $\mathrm{VV}$ polarisation compared to $\mathrm{VH}$ one, $\mathrm{VV}$ polarisation is more accurate owing to significant convergence with the report of losses. The destroyed vegetation area based on VV and VH represents 78\% and 76\%, respectively. This report was prepared by the local government of ElBuhayra governorate, indicating that the destroyed vegetation area was 23100 ha. Figure 6 provides a mapped comparison between the destroyed vegetation cover from the SAR dual polarisations and the optical dataset. There is a satisfying correlation between the results of the three datasets.

4.2. Second Scenario. The main purpose of the second scenario is the determination of the flood limits which can overlay the vegetation layer to estimate the destroyed vegetation area. The results of this scenario provided the morphometric characteristics and hydrological parameters (see Table 2). The analysis shows that there are 13 main basins which drain directly in Wadi El-Natrun depression causing devastation where the peak discharge ranges from $3.72 \mathrm{~m}^{3} / \mathrm{s}$ to $73.16 \mathrm{~m}^{3} / \mathrm{s}$ and time of peak ranges from 345 to 825 minutes as demonstrated in Figure 7. Each main basin contains subbasins, for example, the main basin number 1 has 4 subbasins where the peak discharge of them was
$13.88 \mathrm{~m}^{3} / \mathrm{s}, 13.55 \mathrm{~m}^{3} / \mathrm{s}, 18.95 \mathrm{~m}^{3} / \mathrm{s}$, and $8.5 \mathrm{~m}^{3} / \mathrm{s}$. Based on the peak flow estimated by the hydrologic model, Manning's values which were determined via LULC map, and the extracted geometric data from HEC-GeoRAS, the flood limits can be delineated by the hydraulic model based on HEC-RAS software.

Based on the characteristics of each basin, the hazard degree can be determined. The results manifested that basins 1 and 13 were classified as very high risk because they have the highest peak discharge of $73.16 \mathrm{~m}^{3} / \mathrm{s}$ and $56.85 \mathrm{~m}^{3} / \mathrm{s}$, high drainage density of 0.91 and 0.97 , ruggedness number of 0.20 and 0.14 , curve number of 80.10 and 78.84 , and the biggest area of $1353 \mathrm{~km}^{2}$ and $392.3 \mathrm{~km}^{2}$, respectively. In addition, basin 1 compared to the thirteen basins has the biggest vegetation area inside the basin while basin 13 is free of the cultivation cover activity. Basins 4 and 5 are categorized as high risk because they have high peak discharge of $44.15 \mathrm{~m}^{3} /$ $\mathrm{s}$ and $45.09 \mathrm{~m}^{3} / \mathrm{s}$, drainage density of 1.08 and 0.97 , ruggedness number of 0.18 and 0.19 , and curve number of 84.61 and 83.40, respectively. Also, these basins have high agricultural activity. Basins 2, 3, and 11 were grouped as moderate risk because they have peak discharge of $27.01 \mathrm{~m}^{3} /$ $\mathrm{s}, 29.85 \mathrm{~m}^{3} / \mathrm{s}$, and $26.03 \mathrm{~m}^{3} / \mathrm{s}$, drainage density of $0.82,1.15$, and 1.08, and ruggedness number of $0.11,0.16$, and 0.21 , respectively. The activities of these basins are varied among urban and agricultural areas; basin 2 has many archaeological buildings such as Syrian Monastery and Anba Bishoy Monastery besides agricultural activity, while basins 3 and 11 have only agricultural activity. Finally, basins 6, 7, 8, 9, 10, and 12 were characterized as low risk, with low peak discharge. Figure 8 illustrates the degree of hazard of the thirteen main basins.

Lag time is an extremely important element where longer duration permits better warning and evacuation of the urban area located in the downstream area. The results have manifested that basins 2, 3, and 6 have a lag time under two hours, whereas basins $4,5,7,8,9,10$, and 12 have a lag time under 3 hours. For basin 11, it has a lag time of about 4 hours. We can conclude that basins from 2 to 12 represent the first destructive wave because of having influential peak discharge and short lag time. The second destructive wave was generated by basins 1 and 13 because these basins have the highest peak discharge with longer lag time, over 9 hours.

Based on the flood route, the destroyed vegetation area which was concentrated in the downstream area of the main and subbasins is displayed in Figure 9. The results manifested that the destroyed vegetation areas from $1^{\text {st }}$ to $13^{\text {th }}$ basin were $10164.4,243.8,512,789.9,546.1,1156.6,512.8$, 288.5, 1461.9, 296.3, 644.1, 286.6, and 2732 ha, respectively. Consequently, the total destroyed cultivated area was 19635 ha which represents $85 \%$ of the destroyed area mentioned in the local government report. The water depth map shows that the flood depth for the downstream area of the subbasins ranges from $0.24 \mathrm{~m}$ to $6.59 \mathrm{~m}$, with an average of $1.84 \mathrm{~m}$; moreover, the flood depth of the downstream area of the main basins can vary from $0.85 \mathrm{~m}$ to $8.83 \mathrm{~m}$, with an average of $3.25 \mathrm{~m}$. These depths refer to the creation of many ephemeral lakes and the increase of the depth of the existing 


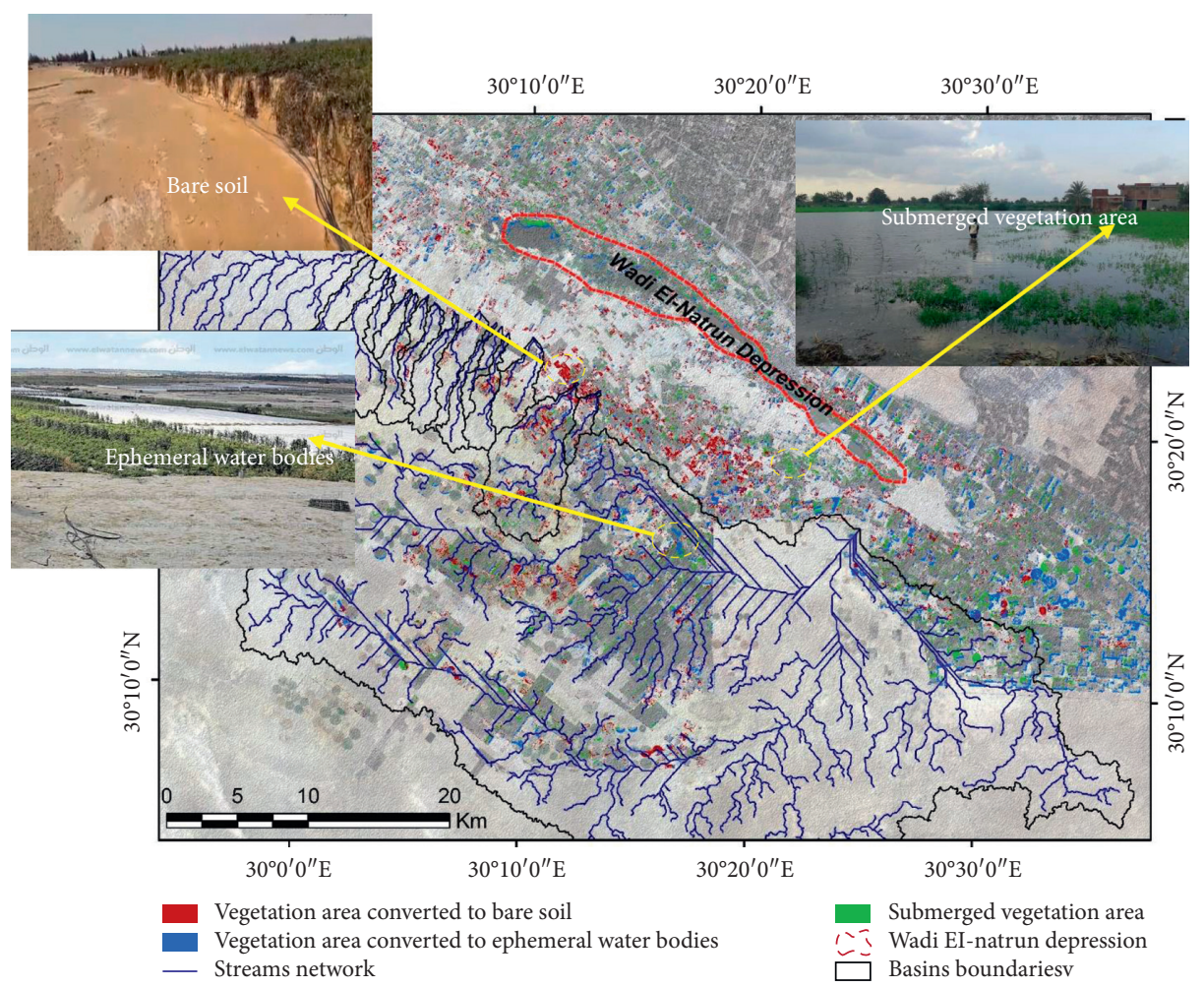

(a)

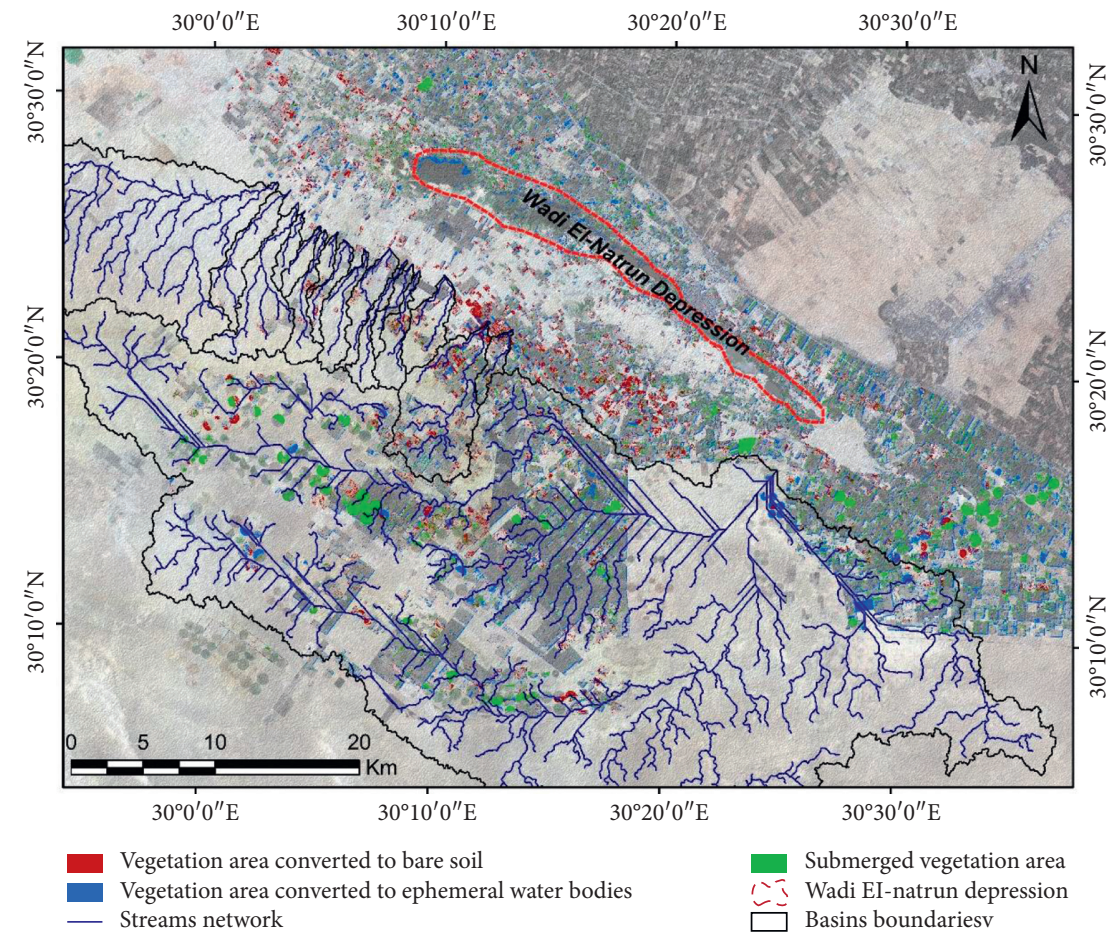

(b)

Figure 5: The output of the first scenario. The destroyed cultivation area (a) from VV polarisation and (b) VH polarisation.

lakes before the flood, where the depths of lakes after the flood from the first to the seventh have become 5.05, 4.27, $4.98,4.75,6.15,0.19$, and $7.54 \mathrm{~m}$ as shown in Figure 10 . Figure 11 demonstrates that many homes were exposed to inundation, estimated above 290 houses among full or partial destruction. Additionally, the segments of the primary road network of Wadi El-Natrun were destroyed, estimated as about $24 \mathrm{~km}$ long. 
TABLE 1: Error matrices showing the accuracy of both polarisations.

\begin{tabular}{lccc}
\hline & & Reference-Sentinel-2 & Row total \\
\hline SAR-Sentinel-1 & No flood & Flood & 141 \\
\hline No flood & 120 & 21 & 167 \\
Flood & 17 & 150 & 308 \\
Column total & 137 & 171 & Overall accuracy \\
Kappa & 0.75 & & 147 \\
$V H$ & 120 & 27 & 170 \\
No flood & 20 & 150 & 317 \\
Flood & 140 & 177 & Overall accuracy \\
Column total & 0.70 & & 85 \\
Kappa & & & \\
\hline
\end{tabular}

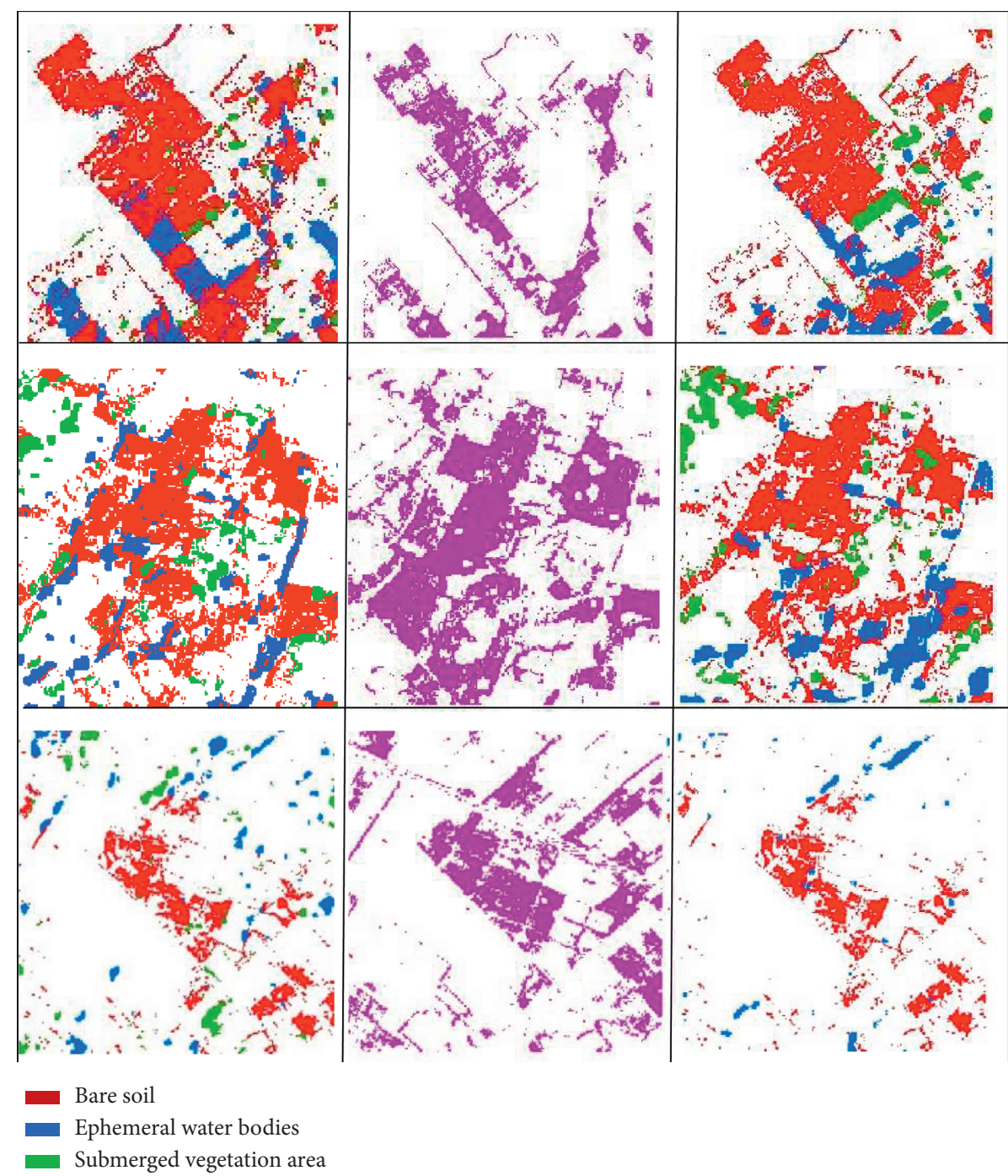

FiguRE 6: Validation of the results of the first scenario using two Sentinel-2 scenes before and after the flood where the change in vegetation cover represents the destroyed vegetation area (the middle images). The right images show the destroyed vegetation area based on $\mathrm{VV}$ polarisation while the left images illustrate the destroyed vegetation area based on VH polarisation.

Based on the visual interpretation of the Sentinel-2 and terrestrial images, (1) the destroyed road network and the ephemeral water bodies were clearly concentrated in
Wadi El-Natrun depression owing to being the lowest area, (2) the floodwater is spread causing difficulty in providing aid, and (3) the pavement layer was changed to 
TABLE 2: The hydrologic parameters and morphometric properties of the main basins and subbasins

\begin{tabular}{|c|c|c|c|c|c|c|c|c|c|c|c|c|}
\hline $\begin{array}{l}\text { Main } \\
\text { basin }\end{array}$ & $\begin{array}{l}\text { Area } \\
(\mathrm{km})\end{array}$ & $\begin{array}{l}\text { Peak } \\
\text { flow }\end{array}$ & $\begin{array}{c}\text { Time of } \\
\text { peak } \\
\text { (minutes) }\end{array}$ & $\begin{array}{l}\text { Volume of } \\
\text { water }\left(\mathrm{m}^{3}\right)\end{array}$ & $\begin{array}{l}\text { TLAG } \\
(\mathrm{h})\end{array}$ & $\begin{array}{r}T_{\mathrm{c}} \\
(\mathrm{h})\end{array}$ & $\mathrm{CN}$ & $\mathrm{Rr}$ & $\mathrm{Dd}$ & $\mathrm{Rn}$ & $\begin{array}{c}\text { No. of } \\
\text { subbasins }\end{array}$ & Peak flow of subbasin \\
\hline 1 & 1353.01 & 73.16 & 705 & 2374708.05 & 10.66 & 17.77 & 80.10 & 0.003 & 0.911 & 0.202 & 4 & $\begin{array}{c}1=13.88,2=13.55 \\
3=18.85,4=8.50\end{array}$ \\
\hline 2 & 26.77 & 27.01 & 345 & 368124.30 & 1.15 & 1.92 & 85 & 0.002 & 0.82 & 0.11 & 3 & $\begin{array}{c}1=2.85,2=4.38 \\
3=5.83,4=5.6\end{array}$ \\
\hline 3 & 31.67 & 29.85 & 360 & 428023.80 & 1.55 & 2.58 & 84.5 & 0.01 & 1.15 & 0.16 & 4 & $\begin{array}{l}1=6.05,2=1.66 \\
3=2.17,4=3.24\end{array}$ \\
\hline 4 & 71.49 & 44.15 & 360 & 891611.10 & 2.74 & 4.57 & 84.61 & 0.01 & 1.08 & 0.18 & 7 & $\begin{array}{c}1=1.28,2=0.99, \\
3=1.02,4=1.31, \\
5=0.99,6=1,7=1.52\end{array}$ \\
\hline 5 & 71.42 & 45.09 & 345 & 836328.60 & 2.88 & 4.80 & 83.4 & 0.008 & 0.97 & 0.19 & 10 & $\begin{array}{c}1=1.05,2=2.79 \\
3=1.72,4=3.1 \\
5=2.28,6=3.48 \\
7=1.00,8=2.28 \\
9=1.6,10=1.04\end{array}$ \\
\hline 6 & 14.52 & 11.43 & 360 & 162930.60 & 1.73 & 2.88 & 84.23 & 0.012 & 0.861 & 0.162 & 1 & $1=4.49$ \\
\hline 7 & 43.90 & 12.34 & 405 & 223307.10 & 2.97 & 4.95 & 82.65 & 0.012 & 1.17 & 0.249 & 4 & $\begin{array}{l}1=1.48,2=0.70 \\
3=0.71,4=2.22\end{array}$ \\
\hline 8 & 16.24 & 3.72 & 450 & 70902.00 & 2.84 & 4.73 & 82.32 & 0.012 & 1.06 & 0.212 & 1 & $1=1.22$ \\
\hline 9 & 18.72 & 5.59 & 405 & 93768.30 & 2.89 & 4.82 & 82.45 & 0.013 & 0.927 & 0.172 & 1 & $1=2.17$ \\
\hline 10 & 12.99 & 6.04 & 405 & 102237.30 & 2.54 & 4.23 & 84.72 & 0.12 & 1.39 & 0.256 & 1 & $1=1.31$ \\
\hline 11 & 79.09 & 26.03 & 435 & 591705.05 & 3.99 & 6.65 & 81.37 & .008 & 1.08 & 0.210 & 4 & $\begin{array}{l}1=3.76,2=2.45 \\
3=3.29,4=2.28\end{array}$ \\
\hline 12 & 13.30 & 6.51 & 390 & 90704.70 & 2.22 & 3.7 & 80.11 & .009 & 1.051 & 0.147 & 1 & $1=2.97$ \\
\hline 13 & 392.3 & 56.85 & 825 & 3688081 & 9.34 & 15.57 & 78.84 & .003 & 0.967 & 0.1365 & - & - \\
\hline
\end{tabular}

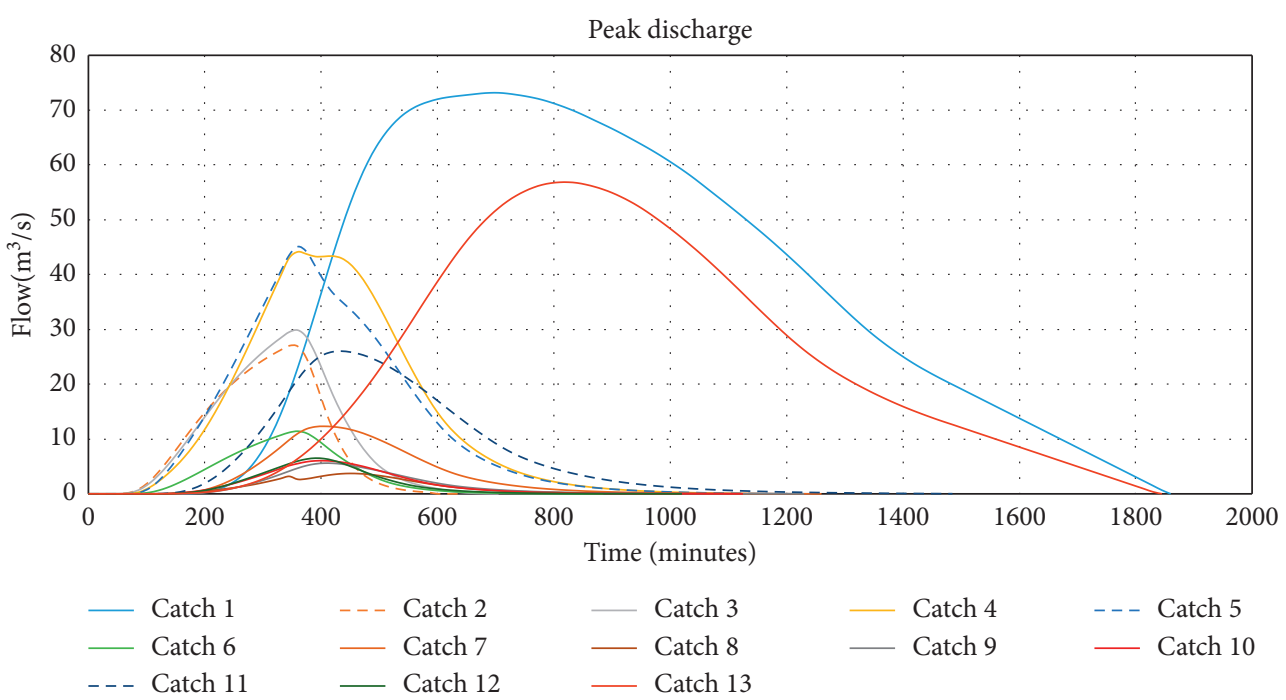

Figure 7: The modeled hydrographs showing the range of the peak discharge of the thirteen main basins in Wadi El-Natrun depression.

sandy layer and water bodies. Figure 12 shows the areas covered by terrestrial images after the flash flood. Figure 13 shows that the route of the flash flood extracted from the hydraulic model coincides with the destroyed areas that appeared on both the Sentinel- 2 and terrestrial images, for instance, the paved road number 1 was converted to water bodies. It furthermore shows the terrestrial images which can contribute to the evaluation of the approximate depth of water and the destroyed infrastructure.
The extracted flash flood route confirmed that the regions outside the flood boundaries never be influenced. However, because of the three walls through the flood route, the direction of the water flow has deviated causing the submergence of other features outside the delineated route, such as Anba Bishoy Monastery and Syrians Monastery. The terrestrial images captured after the flood manifested that due to the rush of the flash flood water, the three walls (the external walls of the monasteries) were exposed to devastation, estimated as about $500 \mathrm{~m}$ long (see Figure 14). 


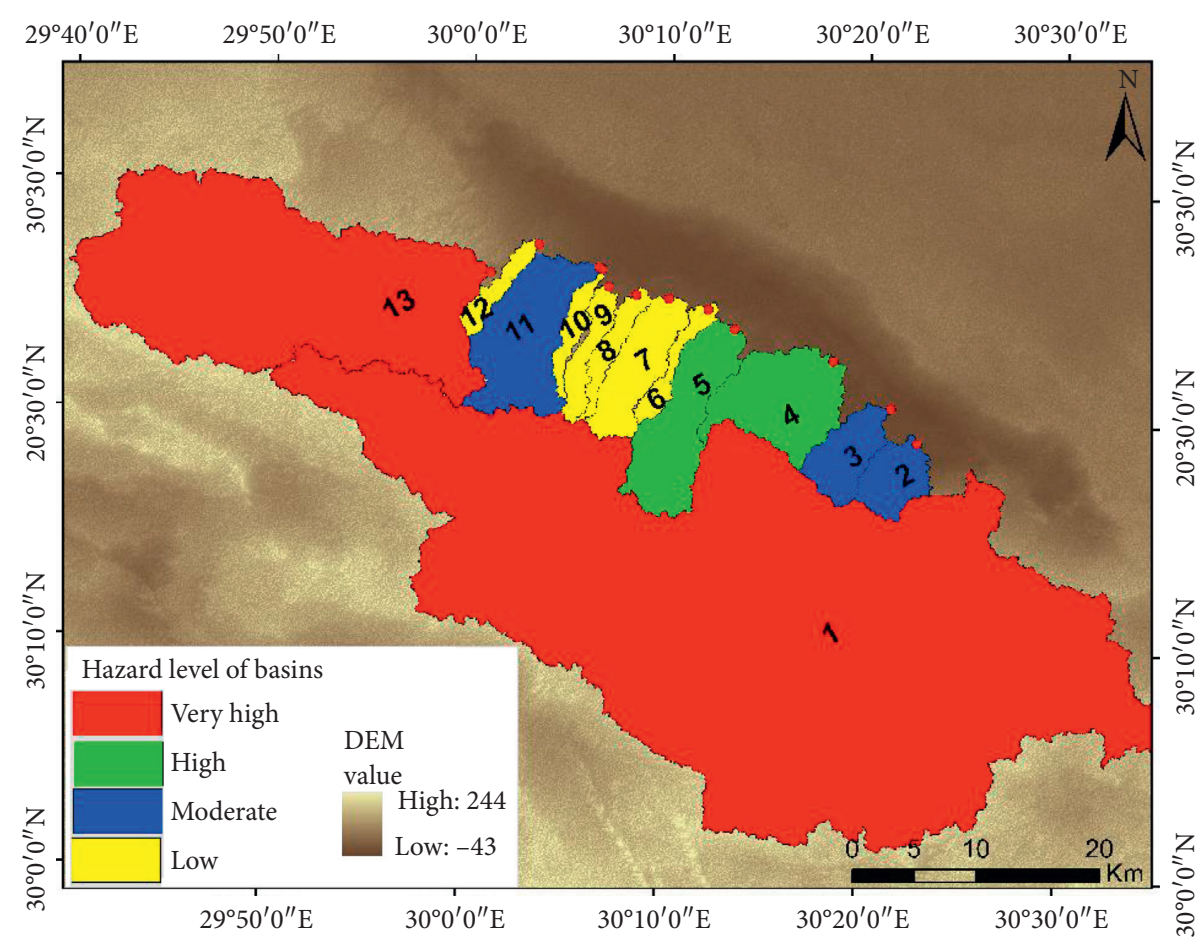

FIGURE 8: The hazard levels of the main basins based on their characteristics, peak discharge, drainage density, and curve number and area properties.

Google Earth images with very high resolution are appropriate to cooperate with the terrestrial images for precise assessment of the destroyed area. In contrast, the Sentienl-2 image is not convenient as the features do not clearly appear. The Google images assist to classify streets having a complete or partial paving layer that help the decision-maker to evaluate the initial cost of the street network fixing.

\section{Discussion and Conclusions}

In this work, we have proposed two scenarios of the methodology to estimate the flash flood impacts on the vegetation cover using low-cost solutions based on available free remote sensing data, GIS techniques, and hydrological and hydraulic models, along with available terrestrial images after the flash flood event directly. Two scenarios were employed as follows.

The first scenario relied on the integration of Sentinel-1 and Sentinel-2 data where the two Sentinel-1 C-band image dual polarisations $\mathrm{VV}-\mathrm{VH}$ acquired before and after the flash flood were utilized to extract the change in the ephemeral water bodies and delineate the flooded vegetation area. Moreover, the two Sentinel-2 images, before and after the flood, were used to extract the change in the bare soil class. Finally, in order to identify the total destroyed vegetation area, the change in the ephemeral water bodies extracted from the CDAT technique between the two Sentinel-1 images and the change in the bare soil extracted from the change detection between the two Sentinel-2 images have overlaid the vegetation cover extracted from Sentinel-2 before the flood. The outputs of the first scenario include a map of vegetation cover converted to water bodies, submerged vegetation area, and bare soil. The results of the first scenario exhibited that the total destroyed vegetation area represents 18119.8 ha $(78 \%)$ using VV polarisation image and 17478.2 ha using $\mathrm{VH}$ polarisation image representing $76 \%$ of the estimated area mentioned in the report of local government, which was 23100 ha.

The outputs of the first scenario are more representative where the map showed the destroyed vegetation area in detail (in the three forms of destruction). However, the lack of Sentinel-2 images availability during the flash flood will disable the assessment of the flash flood impacts. Furthermore, the SAR images captured after the flash flood event should be treated very carefully because the flooded vegetation area extracted from Sentinel-1 data appeared as numerous dispersed spots.

In spite of providing freely available and timely information regarding water body locations, Sentinel-1 C-band radar may be limited in its capacity to supply a signal from submerged vegetation areas. Future provision of freely available L- or P-band imagery will improve the classification of the submerged vegetation area, especially for regions with dense canopies.

Although the CDAT method is an efficient tool to differentiate the submerged vegetated area and the water bodies, the threshold value needs to be defined for each SAR scene which means the need of user intervention. Finally, the first scenario is an effective solution in case of available SAR and optical images before and after the flash flood.

The second scenario was implemented using the remote sensing data and hydrologic/hydraulic models along with GIS to simulate the flash flood behavior. The 


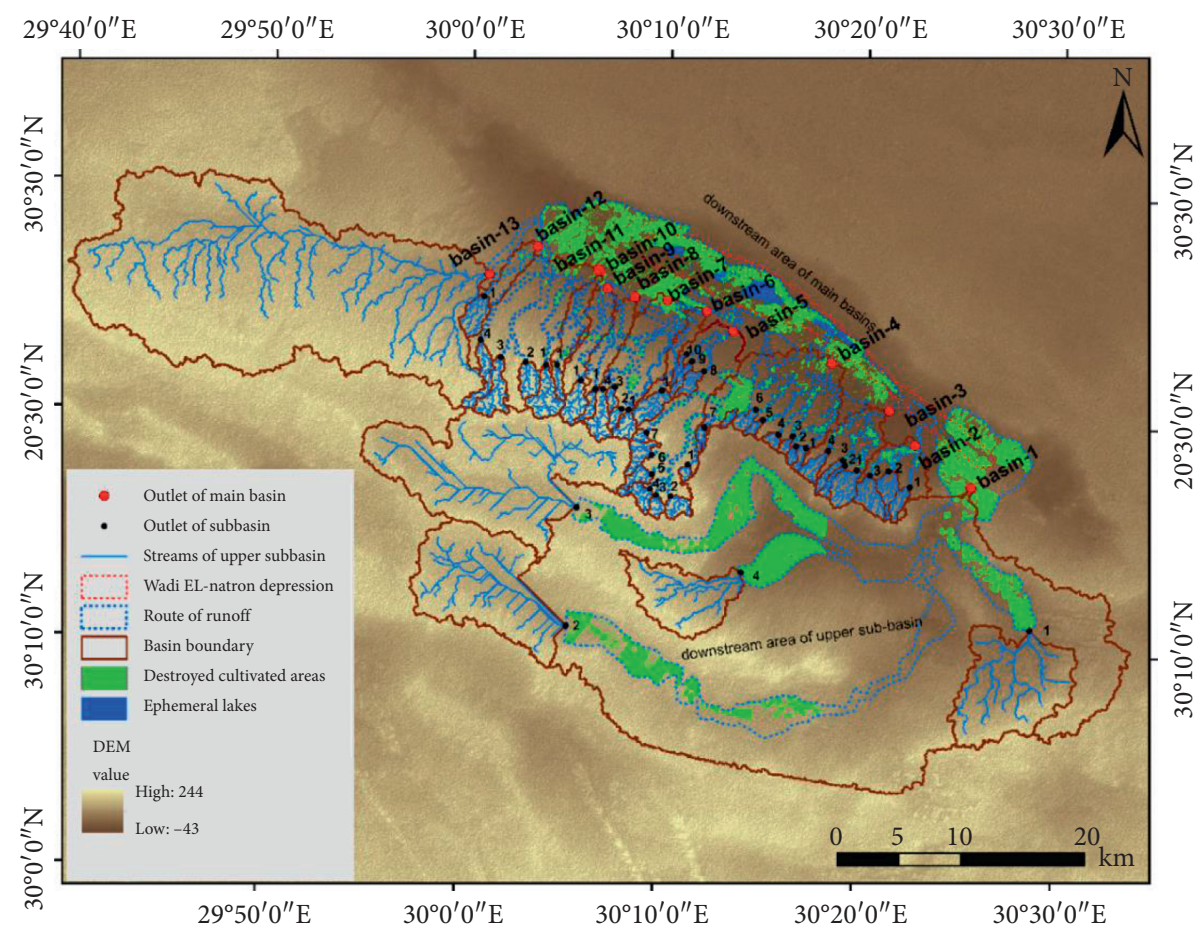

Figure 9: The destroyed vegetation cover determined by overlaying the runoff route on the vegetation cover before the flood.

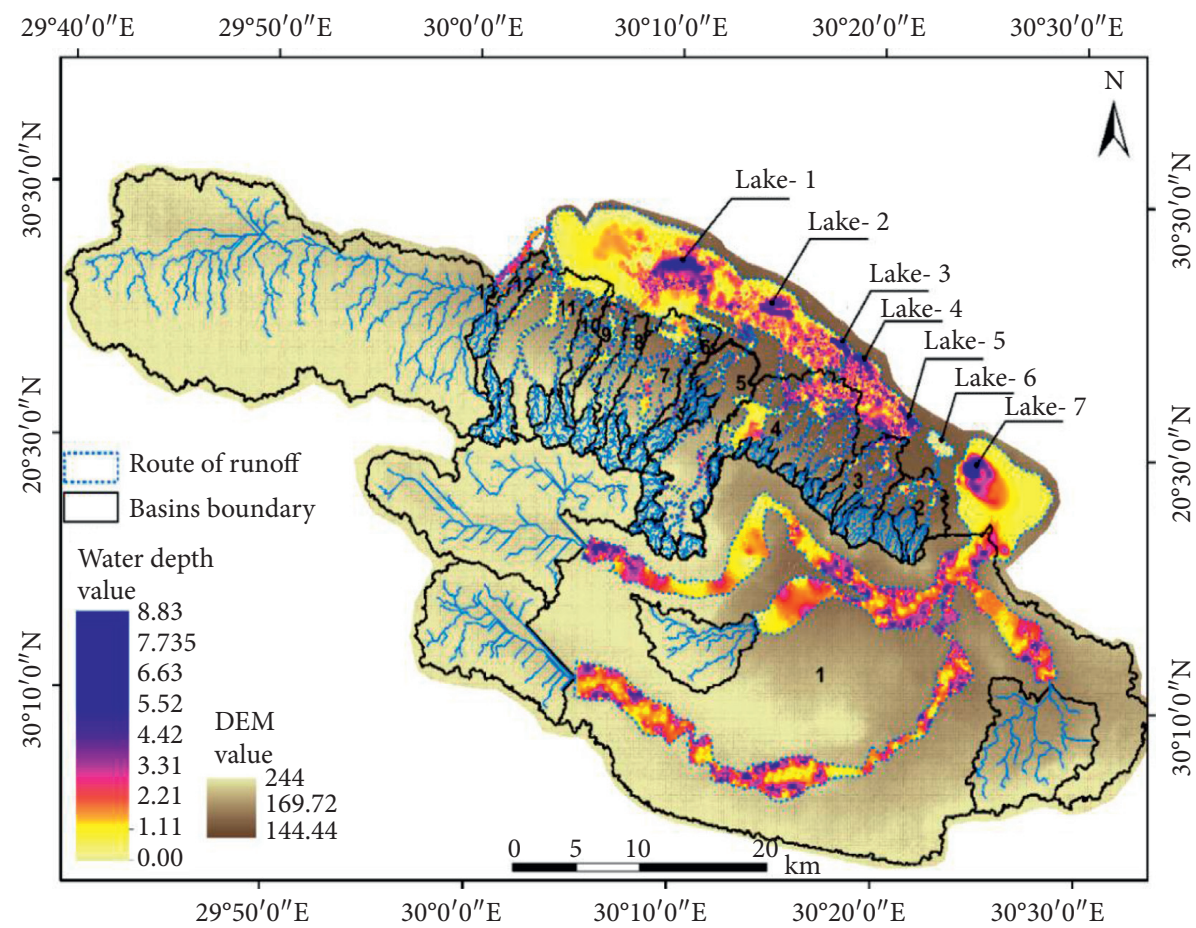

FIgURE 10: The water depth map of the downstream area of the main basins and subbasins.

Sentinal-2 image before the flood was used to obtain the LULC map merged with the geological map to produce the curve number map which was adjusted according to AMC-I. The results of the second scenario provided a hydrologic model regarding the peak flow, the lag time, and the water volume of the basins. Based on the morphometric and hydrologic characteristics, we could determine the hazard degree of each basin where the basin with high peak discharge, high drainage density, high curve number, and a large area is the most dangerous basin which leads to massive flash floods and losses in the agricultural sector. 


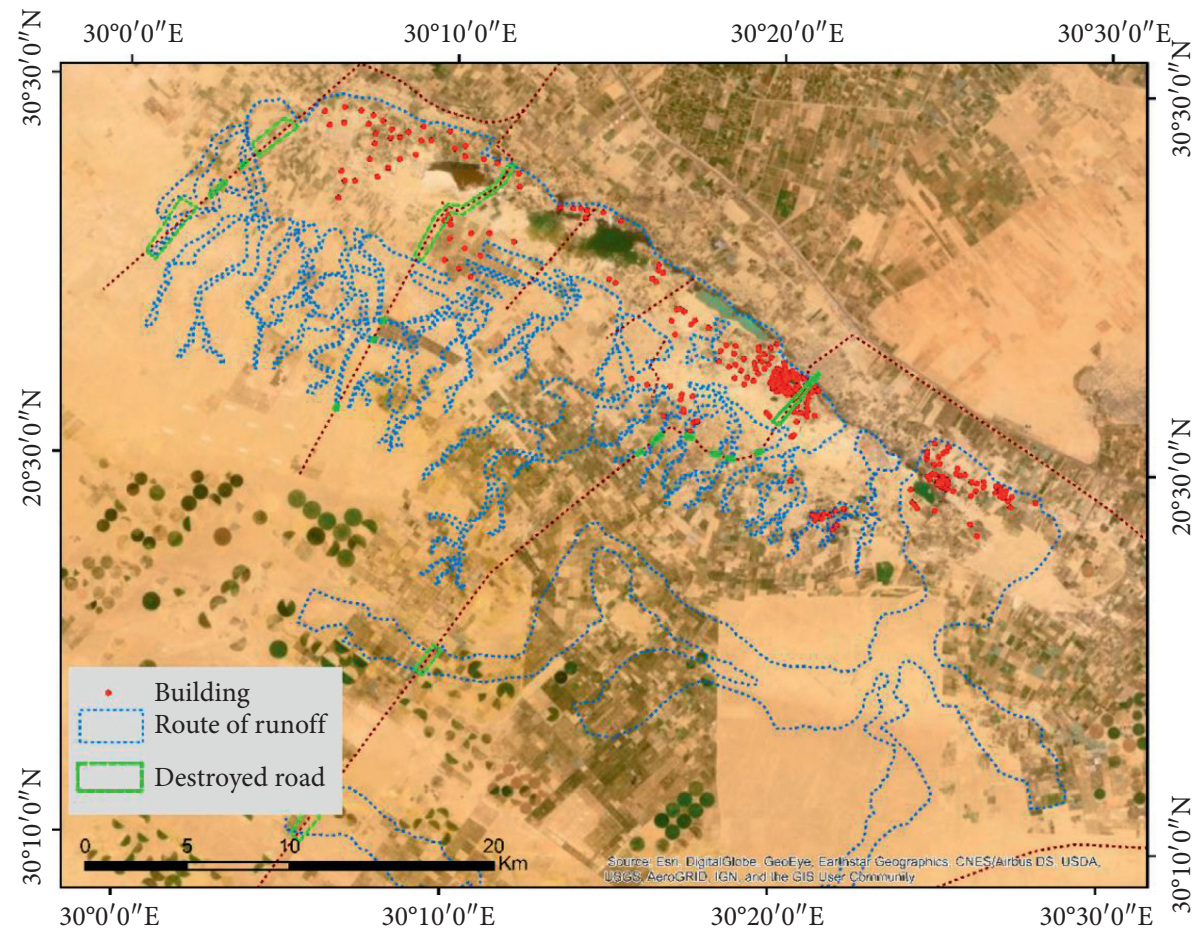

Figure 11: The demolished Infrastructure where the segments of the primary road network were exposed to devastation totally, estimated as about $24 \mathrm{~km}$ long. Furthermore, many homes were exposed to inundation.

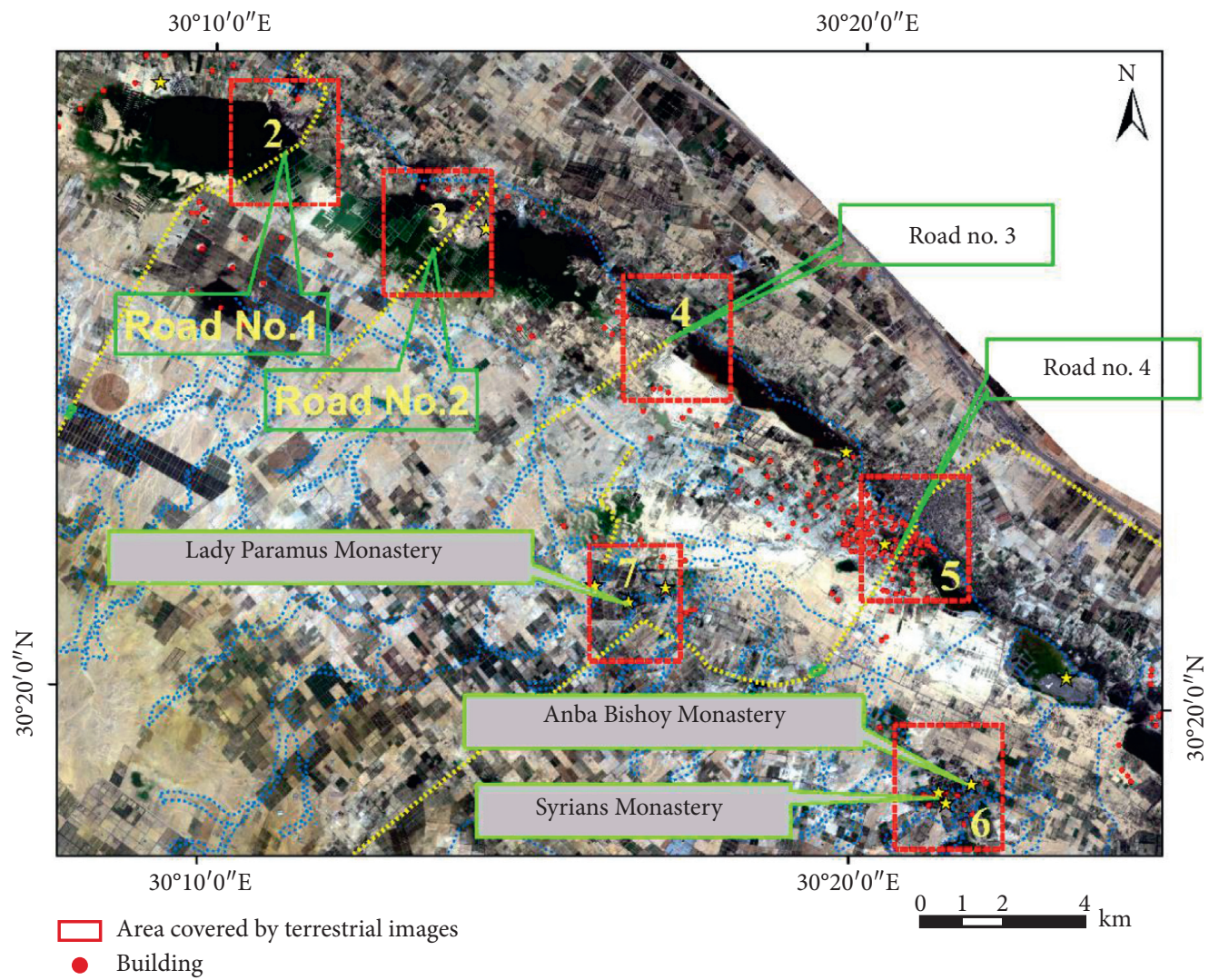

FIGURE 12: The streets through the study area in addition to the areas covered by terrestrial images after the flash flood. 


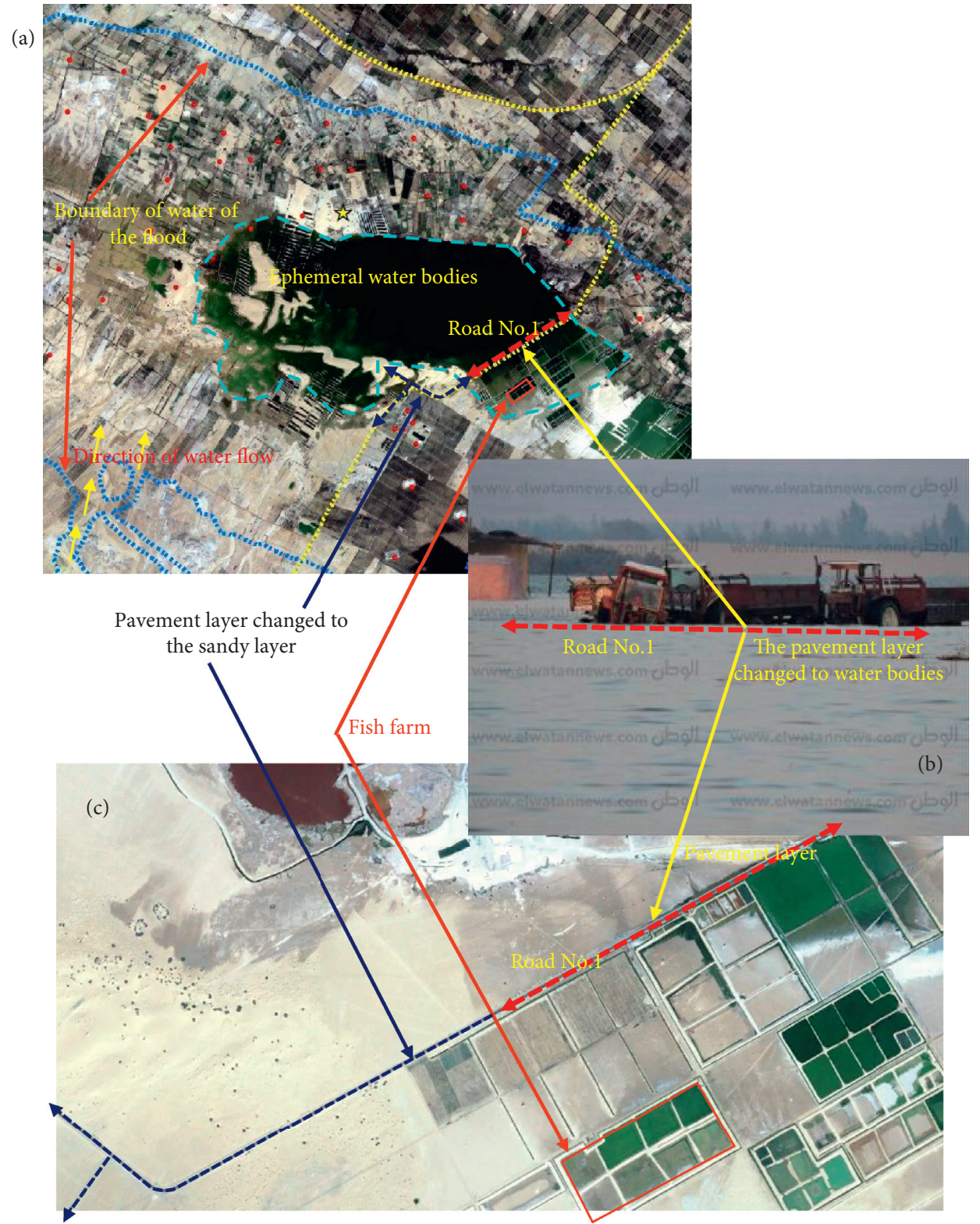

Figure 13: Destroyed road no.1. (a) Sentinel-2 image captured after the flood, (b) Terrestrial images indicating the water depth, and (c) the Google Earth image which presents the pavement layer.

The results illustrated that basins 1 and 13 were classified as very high risk whereas basins 4 and 5 were ranked as high risk. Furthermore, basins 2, 3, and 11 were categorized as moderate risk followed by basins $6,7,8,9,10$, and 12, considered as low risk. The hydrologic model can contribute to flood risk management, decision making of flood mitigation, and establishment of an early warning system based on the lag time which is regarded as the important key for warning and evacuation of the urban area located in the downstream area. Hydraulic modeling was implemented using HEC-RAS and ArcGIS software to simulate the flash flood route. Among the required inputs for the hydraulic modeling are Manning's value, the derived geometric data, and the peak flow. The outcomes of the hydraulic modeling were the spatial extent of the water flow and the flood depth. The derived route of the flood overlaid the vegetation cover to estimate the destroyed vegetation area.

The results demonstrated that the total destroyed cultivation area was 19635 ha which represents $85 \%$ of the destroyed area mentioned in the local government report. The integration of high-resolution Google Earth images and the runoff route assisted in flood risk management to estimate the destroyed buildings and roads. About 290 houses have been destroyed among full or partial destruction; in addition, about $24 \mathrm{~km}$ long of the road network was exposed to destruction as well. In summary, the second scenario assisted local governments, flood risk managers, and decision-makers in preparing for probable 


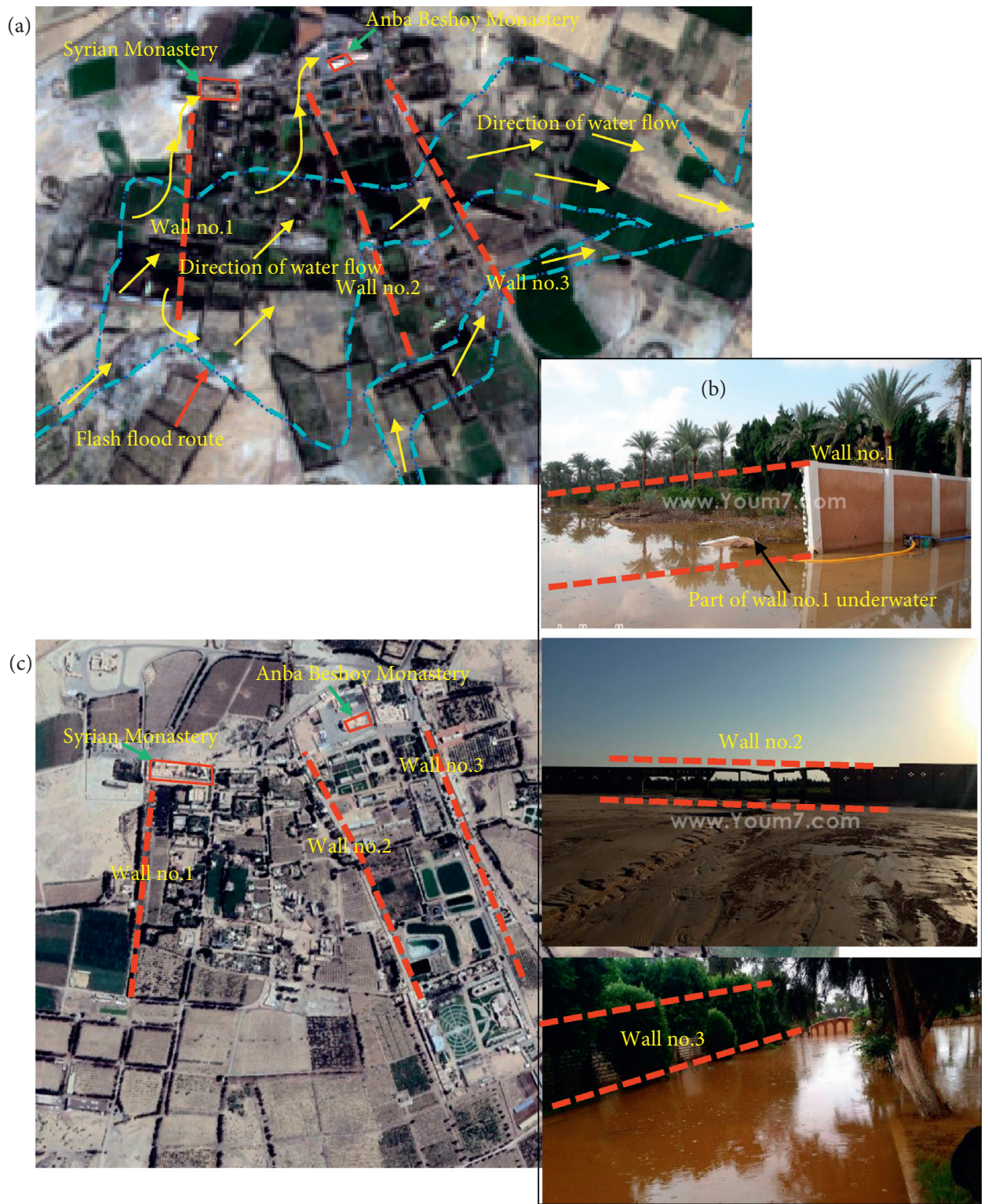

FIgURE 14: (a) The flood route extracted from the hydraulic model was delineated on the post-flash flood Sentinel-2 image, (b) terrestrial images of the destroyed walls which were located through the flood route, and (c) Google Earth image with higher spatial resolution.

flooding when the rains come or, on the other hand, proactively encourage the convenient land-use policy that will minimize the threat to lives and properties caused by flooding. Hence, the second scenario has given outputs, confirming that it is the pioneer, so we recommend the application of the second scenario or adopt the first one in case of available Sentinel-2 satellite images. Sentinel-2 images are capable of validating second scenarios. In case of unavailable Sentinel-2, either terrestrial images or aerial photos (if available) can be relied on.

Although Bishoy Monastery and Syrians Monastery are not inside the runoff route, they were exposed to the flash flood impacts because of the three walls built across the runoff route leading to the change of the water flow direction. So, we have to monitor the human activity in the basin.
So as to obtain results as close as possible to the real situation, with a minimum mistake, it is requisite to improve the accuracy of DEM using Lidar data and up-to-date map of the basins which result in a precise estimate of the area affected. Finally, the videos and photos from Internet web pages and social media proved their benefit in improving the mapping of the flooded area.

Although the step of model calibration is important to improve the model parameters, therefore increasing the accuracy of the model outputs, the basins are ungauged, and there is no meteorological and hydrological data for them. The authors recommend the government to establish the required protective works and the observation stations for meteorological and hydrological data; especially, the study area is recently, unlike the past, susceptible to the frequent destructive flash floods. 


\section{Data Availability}

The Sentinel-2 satellite data images used to support the findings of this study are accessible through https:// earthexplorer.usgs.gov/(before the flood event 16/8/2015: S2A_OPER_MSI_L1C_TL_EPA_20150816T085327_20160 921T091120_A000776_T36RTU_N02_04_01.zip and after the flash flood 14/11/2015: S2A_OPER_MSI_L1C_TL_EPA_20151114T085456_20161224T180133_A002063_T36R TU_N02_04_01.zip). The Sentinel-1 satellite data images used to support the findings of this study are accessible through https://search.asf.alaska.edu/\#/ (before the flood event 9/10/2015 S1A_IW_GRDH_1SDV_20151009T 160424_20151009T160449_008078_00B51E_2F90.zip and after the flash flood 14/11/2015: S1A_IW_GRDH_ 1SDV_20151114T160429_20151114T160454_008603_00C354_ 48A5.zip). Digital soil map and SRTM DEM one arc-second used to support the findings of this study are obtained from the Egyptian Geological Authority, https://earthexplorer.usgs.gov/ respectively.

\section{Conflicts of Interest}

The authors declare that they have no conflicts of interest.

\section{Acknowledgments}

The authors would like to thank Professor Li Xuxiang for the continuous support and also Dr. Hou Kang for his help and Chinese Scholarship Council for financial support. This work was funded by the Ministry of Science and Technology of the People's Republic of China (2013FY112500).

\section{Supplementary Materials}

(1) Visual interpretation of Sentinel-2 images. (2) Visual interpretation of Sentinel-1 images. (3) Results of Sentinel-2. (4) Results of hydrological and hydraulic modeling. (5) Validation of the outputs of the hydrologic/hydraulic modeling based on Sentinel-2 images and terrestrial images. (6) Videos and links. Figure 1: good performance to delineate the several ephemeral lakes using Sentinel-2. (a) Preflash flood and (b) post-flash flood. Based on the visual interpretation, the water bodies were concentrated in Wadi A-Natrun depression. Red rectangle illustrates the location of water bodies. Figure 2: vegetation cover converted to ephemeral water bodies. Figure 3: vegetation cover converted to bare soil after the flood. Figure 4: study area before and after the flash flood based on band combination. (a) Preflash flood and (b) post-flash flood. Figure 5: Sentinel-1 images of the study area. (a) Pre-flash flood and (b) postflash flood. Figure 6: the yellow polygons in the upper images show the vegetation cover before the flood which converted to ephemeral water bodies in the lower images after the flood. The water bodies appear dark because they are smooth surface. Figure 7: the upper images show the vegetation cover before the flood which converted to submerged vegetation area in the lower images after the flood. The down images are shown brighter than upper ones because of the double bounce phenomenon. Figure 8: histogram of the differenced image. Figure 9: the vegetation cover before and after the flood. (a) Pre-flash flood and (b) post-flash flood. Figure 10: destroyed vegetation area using change detection in vegetation cover. Figure 11: the ephemeral water bodies extracted based on ND571 index-(a) pre-flash flood and (b) post-flash flood. Figure 12: flooded vegetation area. Figure 13: $(\mathrm{a}-\mathrm{c})$ rainfall from 3 November $16 \mathrm{pm}$ to 4 November 3 am based on Jaxa Global Rainfall Watch at different time intervals of rainfall. Figure 14: (a) LULC, (b) soil types, (c) the total rainfall from 30 September to 3 November, and (d) storm design. Figure 15: the outputs of hydrologic and hydraulic modeling including profile, 3D model, and peak of flow for basin no.1. Figure 16: the outputs of hydrologic and hydraulic modeling including profile, 3D model, and peak of flow for basin no.2. Figure 17: the outputs of hydrologic and hydraulic modeling including profile, 3D model, and peak of flow for basin no.3. Figure 18: the outputs of hydrologic and hydraulic modeling including profile, 3D model, and peak of flow for basin no.4. Figure 19: the outputs of hydrologic and hydraulic modeling including profile, 3D model, and peak of flow for basin no. 5 . Figure 20: the outputs of hydrologic and hydraulic modeling including profile, 3D model, and peak of flow for basin no. 6 . Figure 21: the outputs of hydrologic and hydraulic modeling including profile, 3D model, and peak of flow for basin no. 7 . Figure 22: the outputs of hydrologic and hydraulic modeling including profile, 3D model, and peak of flow for basin no. 8 . Figure 23: the outputs of hydrologic and hydraulic modeling including profile, 3D model, and peak of flow for basin no.9. Figure 24: the outputs of hydrologic and hydraulic modeling including profile, 3D model, and peak of flow for basin no. 10. Figure 25: the outputs of hydrologic and hydraulic modeling including profile, 3D model, and peak of flow for basin no.11. Figure 26: the outputs of hydrologic and hydraulic modeling including profile, 3D model, and peak of flow for basin no.12. Figure 27: the outputs of hydrologic and hydraulic modeling including profile, 3D model, and peak of flow for basin no.13. Figure 28: all the areas covered by terrestrial images after the flash flood. Subpart (a) in Figures 28, 29, 30, 31, 32, and 33 represents the images captured by Sentinel-2. Subpart (b) in Figures 28, 29, 30, 31, 32 , and 33 represents the Google image. Furthermore, subpart (c) in Figures 28, 29, 30, 31, 32, and 33 represents terrestrial images. Figure 35: the destroyed infrastructure outputs (road network) which were extracted by hydrologic/ hydraulic modeling can be validated by Sentinel-2 images. Figure 36: the destroyed infrastructure outputs (road network) which were extracted by hydrologic/hydraulic modeling can be validated by Sentinel-2 images. Figure 37: the destroyed infrastructure outputs (road network) which were extracted by hydrologic/hydraulic modeling can be validated by Sentinel-2 images. Figure 38: the similarity area for lake 3 between water bodies extracted from Sentinel-2 and water bodies from hydrologic/hydraulic modeling. Table 1: different antecedent moisture condition. Table 2: correlation between ephemeral water bodies from Sentinel-2 and lakes created by hydrologic/hydraulic modeling. (Supplementary Materials) 


\section{References}

[1] M. Sadek and X. Li, "Low-cost solution for assessment of urban flash flood impacts using sentinel-2 satellite images and fuzzy analytic hierarchy process: a case study of ras ghareb city, Egypt," Advances in Civil Engineering, vol. 2019, Article ID 2561215, 15 pages, 2019.

[2] M. J. Hammond, A. S. Chen, S. Djordjević, D. Butler, and O. Mark, "Urban flood impact assessment: a state-of-the-art review," Urban Water Journal, vol. 12, no. 1, pp. 14-29, 2015.

[3] D. Aifantopoulou, "Copernicus emergency management Service," 2016, http://emergency.copernicus.eu/mapping/listofcomponents/EMSR192/ALL/EMSR192_18MONCALIERI.

[4] J. Amini, "A method for generating floodplain maps using IKONOS images and DEMs," International Journal of Remote Sensing, vol. 31, no. 9, pp. 2441-2456, 2010.

[5] Y. Wang, J. D. Colby, and K. A. Mulcahy, "An efficient method for mapping flood extent in a coastal floodplain using Landsat TM and DEM data," International Journal of Remote Sensing, vol. 23, no. 18, pp. 3681-3696, 2002.

[6] T. Gerl, M. Bochow, and H. Kreibich, "Flood damage modeling on the basis of urban structure mapping using highresolution remote sensing data," Water, vol. 6, no. 8, pp. 2367-2393, 2014.

[7] F. B. Zhao, Y. P. Wu, L. J. Qiu et al., "Parameter uncertainty analysis of the SWAT model in a mountain-loess transitional watershed on the Chinese loess plateau," Water, vol. 10, no. 6 , p. 690, 2018.

[8] M. Ahmed, K. Rahaman, A. Kok, and Q. Hassan, "Remote sensing-based quantification of the impact of flash flooding on the rice production: a case study over northeastern Bangladesh," Sensors, vol. 17, no. 10, p. 2347, 2017.

[9] F. Gascon, C. Bouzinac, O. Thépaut et al., "Copernicus Sentinel-2A calibration and products validation status," $R e-$ mote Sensing, vol. 9, no. 6, p. 584, 2017.

[10] D. Alsdorf, E. Rodríguez, and D. Lettenmaier, "Measuring surface water from space," Reviews of Geophysics, vol. 45, 2007.

[11] S. Schlaffer, P. Matgen, M. Hollaus, and W. Wagner, "Flood detection from multi-temporal SAR data using harmonic analysis and change detection," International Journal of Applied Earth Observation and Geoinformation, vol. 38, pp. 15-24, 2015.

[12] D. Giordan, D. Notti, A. Villa et al., "Low cost, multiscale and multi-sensor application for flooded area mapping," Natural Hazards and Earth System Sciences, vol. 18, no. 5, pp. 14931516, 2018.

[13] H. C. Jung, J. Hamski, M. Durand et al., "Characterization of complex fluvial systems using remote sensing of spatial and temporal water level variations in the Amazon, Congo, and Brahmaputra Rivers," Earth Surface Processes and Landforms, vol. 35, no. 3, pp. 294-304, 2010.

[14] P. A. Brivio, R. Colombo, M. Maggi, and R. Tomasoni, "Integration of remote sensing data and GIS for accurate mapping of flooded areas," International Journal of Remote Sensing, vol. 23, no. 3, pp. 429-441, 2002.

[15] T. Y. Gan, F. Zunic, C.-C. Kuo, and T. Strobl, "Flood mapping of Danube River at Romania using single and multi-date ERS2-SAR images," International Journal of Applied Earth Observation and Geoinformation, vol. 18, pp. 69-81, 2012.

[16] J. Mashaly and E. Ghoneim, "Flash flood hazard using optical, radar, and stereo-pair derived dem: eastern desert, Egypt," Remote Sensing, vol. 10, no. 8, p. 1204, 2018.

[17] F. Bioresita, A. Puissant, A. Stumpf, and J.-P. Malet, "A method for automatic and rapid mapping of water surfaces from sentinel-1 imagery," Remote Sensing, vol. 10, no. 2, p. $217,2018$.

[18] N. S. Embabi, "The geomorphology of Egypt, landform and evolution. The nile valley and the western desert," vol. 1, p. 447, Geographic Soc. Spec., Cairo, Egypt, 2004.

[19] F. De Zan and A. Monti Guarnieri, "TOPSAR: terrain observation by progressive scans," IEEE Transactions on Geoscience and Remote Sensing, vol. 44, no. 9, pp. 2352-2360, 2006.

[20] V. Tsyganskaya, S. Martinis, P. Marzahn et al., "Detection of temporary flooded vegetation using sentinel-1 time series data," Remote Sensing, vol. 10, no. 8, p. 1286, 2018.

[21] F. Henderson and A. Lewis, Manual of Remote Sensing: Principles and Applications of Imaging Radar, Wiley, New York, NY, USA, 3rd edition, 1998.

[22] I. H. Woodhouse, Introduction to Microwave Remote Sensing, p. 370pp, CRC Press, Boca Raton, FL, USA, 2006.

[23] L. L. Hess, J. M. Melack, and D. S. Simonett, "Radar detection of flooding beneath the forest canopy: a review," International Journal of Remote Sensing, vol. 11, no. 7, pp. 1313-1325, 1990.

[24] G. J.-P. Schumann, J. C. Neal, D. C. Mason, and P. D. Bates, "The accuracy of sequential aerial photography and SAR data for observing urban flood dynamics, a case study of the UK summer 2007 floods," Remote Sensing of Environment, vol. 115, no. 10, pp. 2536-2546, 2011.

[25] D. C. Mason, I. J. Davenport, J. C. Neal, G. J.-P. Schumann, and P. D. Bates, "Near real-time flood detection in urban and rural areas using high-resolution synthetic aperture radar images," IEEE Transactions on Geoscience and Remote Sensing, vol. 50, no. 8, pp. 3041-3052, 2012.

[26] A. Hardy, G. Ettritch, D. Cross et al., "Automatic detection of open and vegetated water bodies using sentinel 1 to map african malaria vector mosquito breeding habitats," Remote Sensing, vol. 11, no. 5, p. 593, 2019.

[27] J. F. Rosser, D. G. Leibovici, and M. J. Jackson, "Rapid flood inundation mapping using social media, remote sensing and topographic data," Natural Hazards, vol. 87, no. 1, pp. 103120, 2017.

[28] J. Fohringer, D. Dransch, H. Kreibich, and K. Schröter, "Social media as an information source for rapid flood inundation mapping," Natural Hazards and Earth System Sciences, vol. 15, no. 12, pp. 2725-2738, 2015.

[29] F. B. Zhao, Y. P. Wu, Y. Y. Yao et al., "Predicting the climate change impacts on water-carbon coupling cycles for a loess hilly-gully watershed," Journal of Hydrology, vol. 581, Article ID 124388, 2020.

[30] F. Zhao, Y. Wu, B. Sivakumar et al., "Climatic and hydrologic controls on net primary production in a semiarid loess watershed," Journal of Hydrology, vol. 568, pp. 803-815, 2019.

[31] J. Hoffmann and D. Walter, "How complementary are SRTM$\mathrm{X}$ and - $\mathrm{C}$ band digital elevation models?" Photogrammetric Engineering \& Remote Sensing, vol. 72, no. 3, pp. 261-268, 2006.

[32] G. Brunner, HEC--RAS River Analysis System: User's Manual: US Army Corps of Engineers, Institute for Water Resources, Hydrologic Engineering Center, 2001.

[33] G. Brunner, HEC-RAS River Analysis System: Hydraulic Reference Manual, US Army Corps of Engineers, Institute for Water Resources, Hydrologic Engineering Center, 2010.

[34] J. Warner and G. Brunner, HEC-RAS River Analysis System: Applications Guide, US Army Corps of Engineers, Institute for Water Resources, Hydrologic Engineering Center, 2001. 
[35] Y. Mostafa, Comparison of Land Cover Change Detection methodsusingSPOTimages Master of Science, Department of Civil Engineering, Assiut University, Asyut, Egypt, 2006.

[36] Z. Şen, Wadi Hydrology, CRC Press, New York, NY, USA, 2008.

[37] D. Feldman, Hydrologic Modeling System HEC-HMS: Technical Reference Manual, US Army Corps of Engineers, Hydrologic Engineering Center, Davis, CA, USA, 2000.

[38] Soil Conservation Services (SCS) National Engineering Handbook, Section 4: Hydrology, US Department of Agriculture, Soil Conservation Service, Engineering Division, Washington, DC, USA, 1985.

[39] W. Liang, C. Yongli, C. Hongquan, D. Daler, Z. Jingmin, and Y. Juan, "Flood disaster in Taihu Basin, China: causal chain and policy option analyses," Environmental Earth Sciences, vol. 63, no. 5, pp. 1119-1124, 2011.

[40] US DA and SCS. (US Department of Agriculture, Soil Conservation Service), National Engineering Handbook; Section 19, Construction Inspection; U.S., Washington, DC, USA, 1985.

[41] US NRCS (US National Resources Conservation Services), "Urban hydrology for small watersheds," Technical Manual TR55, 1986.

[42] J. Sumarauw and K. Ohgushi, "Analysis on curve number, land use and land cover changes and the impact to the peak flow in the Jobaru River Basin," Japan. International Journal of Civil \& Environmental Engineering, vol. 12, no. 2, pp. 17-23, 2012.

[43] T. Cameron, P. E. Ackerman, and G. I. S. HEC-GeoRAS, "Tools for Support of HEC-RAS Using ArcGIS User's Manual," US Army Corps of Engineers, Institute for Water Resources, Hydrologic Engineering Center (HEC), Davis, CA, USA, 2012. 